\title{
OPEN The first dinosaurs from the Early Cretaceous Hami Pterosaur Fauna, China
}

\author{
Xiaolin Wang ${ }^{1,2,3 凶}$, Kamila L. N. Bandeira ${ }^{4}$, Rui Qiu ${ }^{1,3,5}$, Shunxing Jiang ${ }^{1,2}$, Xin Cheng ${ }^{6,7}$, \\ Yingxia $\mathrm{Ma}^{8}$ \& Alexander W. A. Kellner ${ }^{4}$
}

The Early Cretaceous Hami Pterosaur Fauna in Northwest China preserves a large number of specimens of the sexually dimorphic pteranodontoid pterosaur Hamipterus tianshanensis, including 3D eggs and embryos. During the last decade, several more fossils have been collected in this area, including three somphospondylan sauropod specimens. The first is Silutitan sinensis gen. et sp. nov., which consists of an articulated middle to posterior cervical vertebrae series. The second, Hamititan xinjiangensis gen. et sp. nov., consists of an incomplete articulated caudal sequence that could be assigned to lithostrotian titanosaurs based on the strongly procoelous caudal vertebrae with lateral concave surface, as well as marked ventrolateral ridges. The third specimen consists of four sacral vertebral elements, apparently unfused, with exposed camellate internal bone and regarded as somphospondylan. Cladistic analyses based on different datasets recovered Silutitan sinensis as an euhelopodid closely related to Euhelopus and Hamititan xinjiangensis as a titanosaur. Besides the pterosaur Hamipterus and one theropod tooth, these dinosaurs are the first vertebrates reported in this region, increasing the diversity of the fauna as well as the information on Chinese sauropods, further supporting a widespread diversification of somphospondylans during the Early Cretaceous of Asia.

In last decades, our knowledge about the Cretaceous somphospondylan sauropods taxa is increasing at high rates, especially in China. Important somphospondylan taxa have been reported from different China provinces, including the Early Cretaceous Gobitian, Qiaowanlong, Daxiatitan, Yongjinglong, Huanghetitan liujiaxiaensis from Gansu ${ }^{1-5}$, Euhelopus from Shandong ${ }^{6,7}$, some isolated titanosauriform teeth and Dongbeititan dongi from Liaoning ${ }^{8,9}$, Liubangosaurus from Guangxi ${ }^{10}$, Ruyangosaurus, Baotianmansaurus, Xianshanosaurus, and "Huanghetitan" ruyangensis from Henan $\left({ }^{11-15}\right.$, although Baotianmansaurus has been considered Late Cretaceous in age), and Borealosaurus from Liaoning ${ }^{16}$; and the Late Cretaceous Jiangshanosaurus and Dongyangosaurus from Zhejiang $^{17,18}$, Zhuchengtitan from Shandong ${ }^{19}$, Gannansaurus from Jiangxi ${ }^{20}$, and Huabeisaurus from Shanxi ${ }^{21,22}$. Important somphospondylan taxa were also reported in other East and Southeast Asian countries, including Thailand ${ }^{23}$ and Mongolia ${ }^{24-29}$.

One of the most important areas for vertebrate fossils from China was found in the Tugulu Group of the Junggar Basin, north of the Tian Shan Mountains in Xinjiang, northwestern China. Most of the material came from the Lower Cretaceous lacustrine deposits which yielded several vertebrate fossils since the last century ${ }^{30-32}$. The fossils content consists mainly of the pterodactyloid pterosaurs Dsungaripterus and Noripterus, several dinosaurs, such as the derived stegosaurian Wuerhosaurus ${ }^{31}$, the ceratopsian Psittacosaurus ${ }^{33,34}$, the alvarezsaurid Xiyu$n y k^{3} s^{35}$, the carcharodontosaurid Kelmayisaurus ${ }^{32,36}$, and the coelurosaurs Tugulusaurus and Xinjiangovenator ${ }^{31,32}$. The paleobiota of this area is known as the Wuerho Pterosaur Fauna ${ }^{31}$. The sole sauropod species described from the Tugulu Group so far is Asiatosaurus, composed by a tooth, three incomplete cervical vertebrae and multiple ribs, regarded by some as nomen dubium (e.g. $\left.{ }^{37}\right)$.

\footnotetext{
${ }^{1}$ Key Laboratory of Vertebrate Evolution and Human Origins, Institute of Vertebrate Paleontology and Paleoanthropology, Chinese Academy of Sciences, Beijing 100044, China. ${ }^{2}$ CAS Center for Excellence in Life and Paleoenvironment, Beijing 100044, China. ${ }^{3}$ University of Chinese Academy of Sciences, Beijing 100049, China. "Laboratory of Systematics and Taphonomy of Fossil Vertebrates, Department of Geology and Paleontology, Museu Nacional/Universidade Federal do Rio de Janeiro, Rio de Janeiro 20940-040, Brazil. ${ }^{5}$ Beijing Museum of Natural History, Beijing 100050, China. ' ${ }^{6}$ Laboratório de Paleontologia da URCA, Universidade Regional do Cariri, Rua Carolino Sucupira, s/n, Crato 63100-000, Brazil. ${ }^{7}$ College of Earth Sciences, Jilin University, Changchun 130061, China. ${ }^{8} \mathrm{Hami}$ Museum, Hami 839000, China. ${ }^{\circledR}$ email: wangxiaolin@ivpp.ac.cn; kellner@ mn.ufrj.br
} 

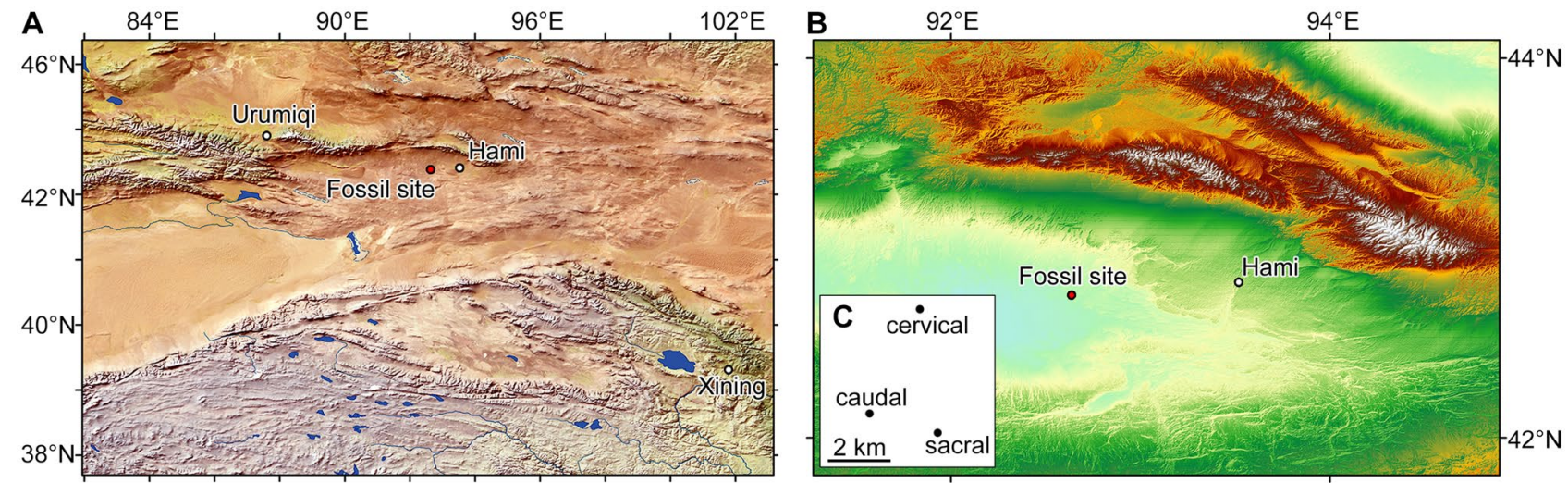

Figure 1. Map showing the fossil site where the new sauropod dinosaur specimens were collected (A,B), and the relative positions of these three specimens $(\mathbf{C})$.

Recently, some interesting fossil sites have been discovered in the Early Cretaceous deposits of the Hami Gobi, more specifically from the Shengjinkou Formation of the Tugulu Group, which is distributed in the Turpan-Hami Basin, south of the Tian Shan Mountains in Xinjiang, China $\left({ }^{38-41}\right.$; Fig. 1). It consists mainly of a large number of pterosaurs, including $3 \mathrm{D}$ eggs $^{40}$ and embryos ${ }^{39,41}$ of the sexually dimorphic pteranodontoid pterosaur Hamipterus tianshanensis. This is one of the few pterosaur bone beds known to date ${ }^{42}$, and provides relevant information on reproduction, development, and habit of these pterosaurs ${ }^{38-41,43,44}$.

Field activities in the Hami region occasionally revealed the presence of other vertebrates, particularly sauropods, that were found by the Hami field team of the IVPP. Among the most important specimens are an incomplete sacral series collected in 2008 (IVPP V27875), a partial tail with an associated theropod tooth recovered in 2013 (HM V22), and a partial articulated sauropod cervical vertebrae series that was associated with a lower jaw of Hamipterus in 2016 (IVPP V27874). Here we describe these materials, that represent a new euhelopodid sauropod (IVPP V27874) and a new titanosaur (HM V22). We also include information of the third specimen (IVPP V27875), an indeterminate somphospondylan. All the studies provide new morphological information of Asian somphospondylan sauropods.

Geological settings. The Tugulu Group is composed of medium-to-fine grained grey-green sandstones alternating with red to brown-red mudstones beds. In Turpan-Hami Basin, this stratigraphic unit includes, from bottom to top, the Sanshilidadun, Shengjinkou, and Lianmuqin formations ${ }^{38,45}$. The Hami Pterosaur Fauna comes from the Shengjinkou Formation whose lacustrine sedimentary sequence is mainly composed by the gray-white sandstones, within some tempestite interlayers made up of brown mudstone breccias ${ }^{38,40,45}$. While almost Hamipterus specimens and their eggs were found in tempestite interlayers ${ }^{40,41}$, the new sauropod specimens were discovered in lacustrine sandstones. The three sauropod specimens were collected from different sites which are 2-5 km away from each other, all showing the presence of Hamipterus. The horizon where the cervical vertebrae sequence (IVPP V27874) was collected is particularly rich in pterosaur specimens. The layers from which the other two sauropod specimens (HM V22 and IVPP V27875) were recovered are positioned about 2 to $3 \mathrm{~m}$ higher than the latter. Occasionally, isolated bones of both, sauropods and theropods (undescribed) are also found.

\section{Background}

Other fossil sites close to the Hami region are the strata from the Junggar Basin, especially the outcrops near the Mazong Mountain ${ }^{46}$. Among the sauropod remains known from the Mazong Mountain (also called the "Mazongshan area"1), are two well-known titanosauriform taxa ${ }^{46}$ : Gobititan shenzhouensis You et al., 2003 (from Gongpoquan Basin) and Qiaowanlong kangxii You \& Li, 2009 (from Yujingzi Basin). From the Junggar Basin, most sauropod taxa are mamenchisaurids (Tienshanosaurus chitaiensis Young, 1937; Mamenchisaurus sinocanadorum Russell \& Zheng, 1994, and Klamelisaurus gobiensis, Zhao, 1993, sensu ${ }^{47}$ ). Fushanosaurus qitaiensis Wang et al., 2019, a putative titanosauriform, was recovered from the Shishugou Formation and is based on a right femur ${ }^{48}$. From all listed somphospondylans recovered from the Mazong Mountain, the only one that shows comparable elements with one of the specimens described here (IVPP V27874-Silutitan) is Qiaowanlong.

Recently, during the redescription of Klamelisaurus by Moore et al. ${ }^{47}$, the phylogenetic analyses conducted using the dataset from Carballido et al. ${ }^{49}$ and González-Riga et al. ${ }^{50}$ found the "core Mamenchisaurus-like taxa" (Klamelisaurus and Mamenchisaurus sinocanadorum included), and some taxa (e.g., Euhelopus) thought to represent somphospondylans outside of Neosauropoda ${ }^{47}$, which is inconsistent with most sauropod cladistics analysis literature ${ }^{49-54}$. It is important to note to the authors highlighted a need for further redescriptions due to conflicting phylogenetic results ${ }^{47}$, as well as revisions of these sauropods (particularly Mamenchisaurus and Omeisaurus). The comparisons with this "core-Mamenchisaurus-like taxa" and consequently full revision of the anatomy and systematics of mamenchisaurids is beyond the scope of this paper.

The specimens described here (IVPP V27874, IVPP V27875 and HM V22) are compared with the following somphospondylans: Abdarainurus barsboldi Averianov \& Lopatin, $2020^{55}$, Baotianmansaurus henanensis Zhang 
et al., 2009 ${ }^{13}$; Daxiatitan binglingi You et al., $2008^{3}$; Dongyangosaurus sinensis Lü et al., 2008 ${ }^{18}$; Erketu ellisoni Ksepka \& Norell, 2006 28,29 , Euhelopus zdanskyi (Wiman, 1929) ${ }^{7,47}$, Gobititan shenzhouensis You et al., 2003'; Huabeisaurus allocotus Pang and Cheng, 200022; Huanghetitan liujiaxiaensis You et al. 20065; "Huanghetitan" ruyangensis Lü et al., 2007 ${ }^{15}$; Jiangshanosaurus lixianensis Tang et al., 2001 17,54; Phuwiangosaurus sirindhornae Martin et al. 1994 $4^{23,47}$ Qiaowanlong kangxii You \& Li, 2009²; Ruyangosaurus giganteous Lü et al., 2009 ${ }^{11,12}$ and Yongjinglong datangi $\mathrm{Li}$ et al., 2014 ${ }^{4}$.Comparisons are also made with the following titanosaur species: Andesaurus delgadoi Calvo and Bonaparte, 1991 56,57; Arrudatitan maximus (Santucci and Arruda-Campos, 2011) ${ }^{58,59}$; Austroposeidon magnificus Bandeira et al., 2016 ${ }^{60}$; Bonatitan reigi Martinelli and Forasiepi, $2004^{61}$; Baurutitan britoi Kellner et al., 2005 ${ }^{62}$; Borealosaurus wimani You et al. 2004 ${ }^{16}$; Dreadnoughtus schrani Lacovara et al., 2014 $4^{63}$; Diamantinasaurus matildae Hocknull et al. 200964; Dongbeititan dongi Wang et al., 20079 ; Epachthosaurus sciuttoi Powell, 199065; Gondwanatitan faustoi Kellner \& Azevedo, 199966; Kaijutitan maui Filippi et al., 2019 ${ }^{67}$; Lirainosaurus astibiae Sanz et al., 1999 ${ }^{68,69}$ Malawisaurus dixeyi Jacobs et al., 1993 ${ }^{70}$; Neuquensaurus australis (Lydekker, 1893) ${ }^{71,72}$; Opisthocoelicaudia skarzynskii Borsuk-Białynicka, 197725; Patagotitan mayorum Carballido et al. 201749; Rapetosaurus krausei Curry-Rogers and Foster, 2001 ${ }^{73}$; Rinconsaurus caudamirus Calvo and González-Riga, 2003 ${ }^{74}$; Saltasaurus loricatus Bonaparte and Powell, 1981 ${ }^{75}$; Tengrisaurus starkovi Averianov and Skutschas, 2017 76,77; Trigonosaurus pricei Campos et al., 2005 $2009^{14}$. Additional anatomical comparisons are made with the titanosaurian pelves described by Campos and Kellner $^{79}$ and by Filipini et al. ${ }^{80}$, and other eusauropods axial remains ${ }^{81-83}$.

\section{Results}

Systematic paleontology. SAUROPODA Marsh, 1878

NEOSAUROPODA Bonaparte, 1986

TITANOSAURIFORMES Salgado et al., 1997

SOMPHOSPONDYLI Wilson \& Sereno, 1998

EUHELOPODIDAE Romer, 1956 (sensu D’Emic, 2012)

Silutitan gen. nov.

ZooBank LSID: urn:lsid:zoobank.org:act:A38DB31D-9375-4D85-A34F-3B099FA19DEF

Type species. Silutitan sinensis sp. nov., type by monotypy.

Etymology. "Silu" means the "Silk Road" in Chinese Mandarin pinyin, in memory the great trade routes which connected the East and West. "titan" means giant in Greek, symbolic of the large size of this genus.

Diagnosis. The same for the species.

Silutitan sinensis new species.

ZooBank LSID: urn:lsid:zoobank.org:act:5486C746-C883-4B9C-BEFB-F711AA122710

Etymology. "sinensis" refers to China, in Latin.

Holotype. An articulated series of six cervical vertebrae (IVPP V27874) with almost all cervical ribs, housed at IVPP (Figs. 2, 3; Table 1).

Locality and Horizon. Hami, Xinjiang, China; Lower Cretaceous Shengjinkou Formation (Tugulu Group).

Diagnosis. An euhelopodid sauropod exhibiting the following autapomorphies found in the cervical vertebrae: (1) ventrolaterally bifurcated postzygodiapophyseal laminae [PODL] in middle to posterior cervical vertebrae, (2) anteriorly bifurcated posterior centrodiapophyseal laminae [PCDL] on the four posterior-most cervical vertebrae, (3) parapodiapophyseal laminae [PPDL] forming developed ventral flanges, (4) contact surface of diapophysis and tuberculum in the middle and posterior cervical vertebrae constricted on anterior and posterior faces. It is further characterized by the following combination of characters: cervical vertebrae with developed epipophyses, prezygodiapophyseal laminae anteriorly projected, lateral pneumatic fossae on centra restricted anteriorly, neural arches with two fossae bordered by the epipophyseal-prezygapophyseal laminae, and the neural spines reduced anteroposteriorly.

Description and comparisons of Silutitan. The specimen IVPP V27874 consists of six articulated cervical vertebrae, some with the respective cervical ribs (Fig. 3). All elements are preserved three dimensionally, with the external bone surface complete but, except for the two last, most lack the neural spine. Based on the Euhelopus 


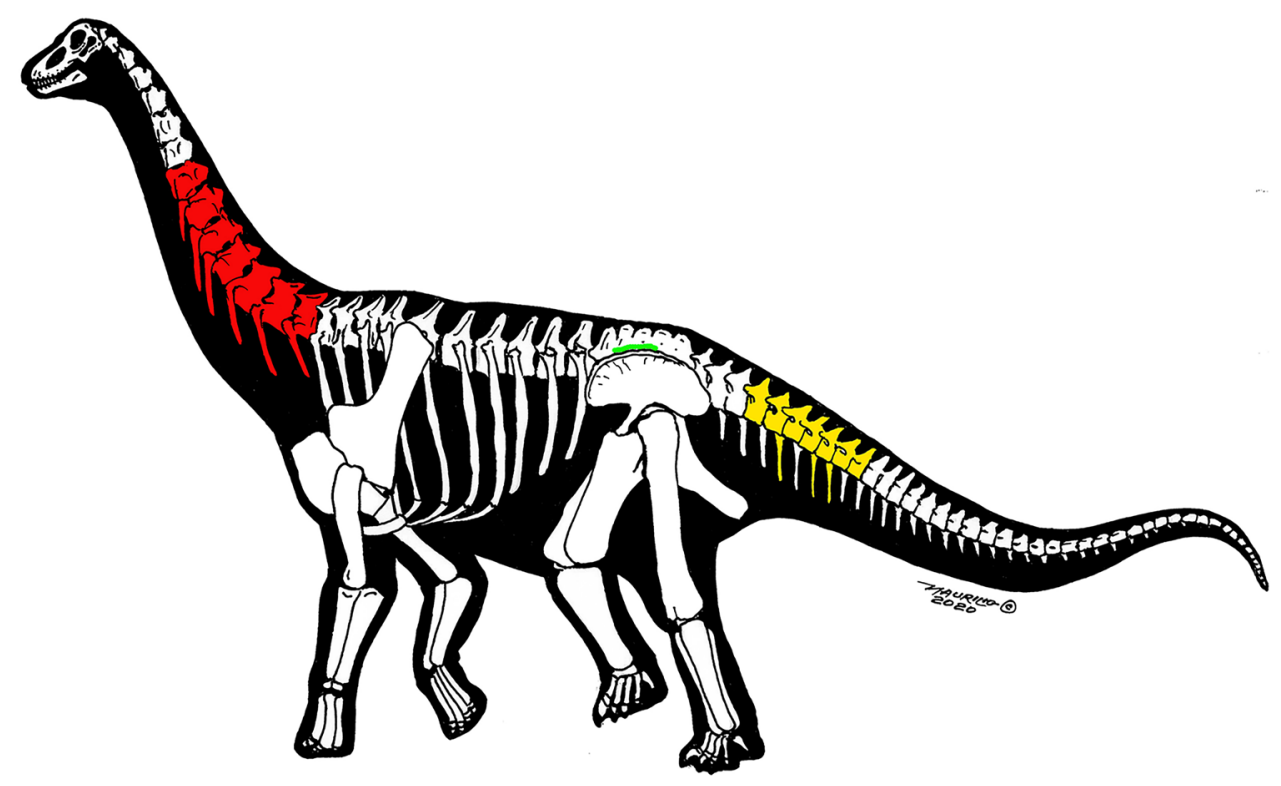

Figure 2. All specimens described in this paper shown in one outline of a generic titanosaur: preserved cervical elements of Silutitan sinensis gen. et sp. nov. (IVPP V27874) (red), preserved caudal elements of Hamititan xinjiangensis gen. et sp. nov. (HM V22) (yellow) and the preserved sacral elements (IVPP V27875) (green). Image credit: Maurílio Oliveira.

zdanskyi neck, one of the most complete Somphospondyli known to date ${ }^{7}$, Silutitan sinensis gen. et sp. nov. (IVPP V27874) represents the cervical sequence 10 to 15 , and we will refer as such. The body length is estimated as $>20 \mathrm{~m}$ by comparison with length of the cervicals of Euhelopus ${ }^{7}$.

All elements are strongly opisthocoelous and decrease gradually in length posteriorly, a common condition for sauropods (Table 1). The articular surfaces seem to be mediolaterally wider than dorsoventrally tall (since its still covered by matrix), similar to Qiaowanlong ${ }^{2}$ but differing from Euhelopus ${ }^{7}$ and Erketu ${ }^{28,29}$. As expected for titanosauriform sauropods and some mamenchisaurids ${ }^{47}$, the vertebrae show camellate pneumatic structure. Silutitan has the lateral margin of the centra slightly excavated, with the pneumatic fossae (pleurocoel) restricted anteriorly and thus differing from Erketu and Euhelopus (Fig. 3). The fossae of the new species are further placed ventral to the diapophysis, which is best observed in cervical vertebra 12 . The parapophysis presents its dorsal surface excavated and deflected ventrally as in Qiaowanlong ${ }^{2}$, Euhelopus ${ }^{7}$ and Erketu ${ }^{28}$. The ventral surfaces are concave and show some sharp ridges formed by the parapodiapophyseal laminae (PPDL), that extend along the ventrolateral edges of the centrum, as in Euhelopus ${ }^{7}$ but less transversely developed in the latter. The PPDL are more ventrally developed than in Euhelopus, forming a flange-like structure, which do not reach the posterior articulation of the centrum (Fig. 3). As in many somphospondylans, Silutitan presents low and anteroposteriolly short neural arch in almost all preserved cervicals, with exception of the last one. The low and anteroposteriolly short neural arches are observed for example, in the euhelopodids Euhelopus ${ }^{7}$, Qiaowanlong ${ }^{2}$ and Erketu ${ }^{28,29}$; in the somphospondylan Phuwiangosaurus ${ }^{23}$ and in the titanosaurs Arrudatitan ${ }^{58}$, Bonatitan ${ }^{61}$ and Trigonosaurus $^{78}$.

The prezygapophyses are relatively large but with thin prezygodiapophyseal laminae (PRDL). The PRDL is anteriorly projected forming a developed flange ("pre-epipophysis", sensu'), which reaches the articular facet of the prezygapophyses. The PRDL forming a developed flange is observed in the somphospondylans Euhelopus $^{7}$, Erketu $^{28,29}$, Phuwiangosaurus ${ }^{23}$, Huabeisaurus ${ }^{22}$ and on the eusauropod turiasaurian Moabosaurus ${ }^{81}$. The epipophyseal-prezygapophyseal lamina (EPRL) is present in all recovered cervical vertebrae (Fig. 3). The EPRL is also observed in Klamelisaurus ${ }^{47}$, in the somphospondylans Euhelopus ${ }^{7,47}$, Qiaowanlong $^{2}$, Phuwiangosaurus ${ }^{23}$ and in the titanosaur Kaijutitan ${ }^{67}$. As in the taxa cited, the EPRL divides the spinodiaphophyseal fossa (sdf) into two subfossae, but more similar to the condition observed in Euhelopus ${ }^{7}$, two subfossae present, one located dorsally (sdf1) and the other ventrally (sdf2). The EPRL is absent in Erketu and only present on the posteriormost cervical vertebrae of Kaijutitan ${ }^{67}$ and in Qiaowanlong ${ }^{2}$, as in some middle to posterior cervical elements of Phuwiangosaurus ${ }^{23}$. Moore et al. ${ }^{47}$ presents an extensive comparative anatomy of the EPRL among Klamelisaurus, Euhelopus, Kaijutitan, and Phuwiangosaurus, as well as other sauropod taxa. But in Kaijutitan and Phuwiangosaurus, the EPRL is almost vertically oriented, while this structure is diagonal in Qiaowanlong, and horizontal in Euhelopus and Silutitan.

The diapophyses are relatively short, directed laterally and curved ventrally, as in several somphospondylans (e.g. ${ }^{27,28,29}$ ). Also, the diapophyses-tuberculum contact surface is constricted anteroposteriorly in the middle and posterior cervical vertebrae. Albeit this feature is presented in 8th cervical of Erketu $\left({ }^{29}:\right.$ Fig. 1C) and in the posterior-most cervical of Euhelopus ( ${ }^{7}$ : Fig. 11$)$ and Daxiatitan $\left({ }^{3}\right.$ : Fig. 1a), we note that is not the same condition as observed in Silutitan. In Euhelopus, Daxiatitan and Erketu, the "constriction" is presented solely on anterior 


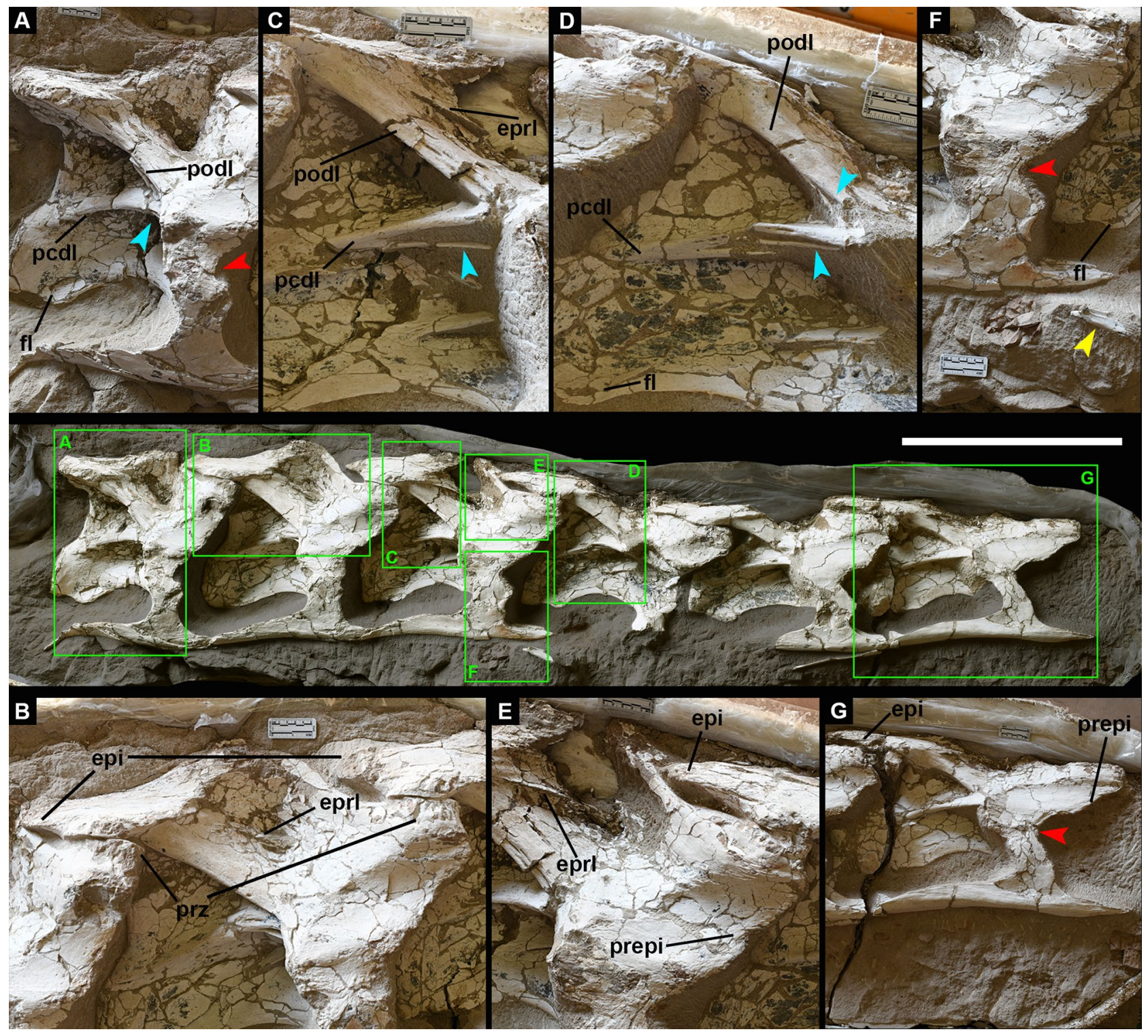

Figure 3. Silutitan sinensis gen. et sp. nov. (holotype-IVPP V27874) in left lateral view. Squares separated by letters indicate relevant anatomical details. (A) Posteriormost cervical vertebrae, with the bifurcated pcdl (posterior centrodiapophyseal lamina) and podl (postzygodiapophyseal lamina). (B) Articulation of cervicals 14 and 15, showing the epiphophysis (epi) and the epipophyseal-prezygapophyseal lamina (eprl). (C) Cervical vertebrae 13 showing details of the eprl, podl and pcdl. (D) Cervical vertebrae 12 showing details of the podl, pcdl and the fl (flange). (E) Cervical vertebrae 12 and 13 with "pre-epipophysis" (prepi), visible eprl and markedly epipopophysis (epi). (F) Cervical vertebra 13 showing well developed lateral flange close to the centrum posterior end. (G) Cervical vertebra 11, with markedly "pre-epipopophysis" (prepi) together with developed epipophysis. Red arrows show the constricted anteroposteriorly diapophyses-tuberculum contact. Blue arrows highlight laminae bifurcations. Yellow arrow indicates associated pterosaur lower jaw. Scale bar: $50 \mathrm{~cm}$.

face at the contact surface of diapophysis and tuberculum, while in Silutitan it is presented on the anterior and posterior faces (Fig. 3).

The new taxon shows a developed posterior centrodiapophyseal lamina (PCDL) that is directed ventroposteriorly and bifurcated in cervical 11 to 15 . Except for the lognkosaurian titanosaur from Brazil, Austroposeidon, (MCT 1628-R, 52), the bifurcation of the PCDL (Fig. 3) in Silutitan is unique. The bifurcation of the PCDL is placed close to the diapophysis and not as posterior as in Austroposeidon, where it originates on the centrum and is not as deep ${ }^{60}$. Also, since Austroposeidon has this feature observable in the posterior-most preserved cervical vertebra, it is unknown if the bifid PCDL was presented along the four last cervical vertebrae (as in Silutitan), what clearly differentiates Silutitan from the Brazilian species. Still regarding the PCDL, this structure differs in the new species from Qiawanlong where it is more horizontal ${ }^{2}$. The postzygodiapophyseal fossae (PODF) in all vertebrae are not so deep as in other somphospondylians but are well delimited by the inclined 


\begin{tabular}{|l|l|l|l|l|l|}
\hline & Maximum length & Epipophysis lenght & Maximum height & Neural arch heigth & CPOL height \\
\hline Cv 10 & 520 & 100 & 260 & $\sim 140$ & $\sim 70$ \\
\hline Cv 11 & 490 & 80 & 270 & $\sim 150$ & n.o \\
\hline Cv 12 & 510 & 90 & 280 & $\sim 190$ & $\sim 110$ \\
\hline Cv 13 & 540 & 550 & 350 & $\sim 245$ & $\sim 140$ \\
\hline Cv 14 & 520 & 650 & 410 & $\sim 230$ & $\sim 170$ \\
\hline Cv 15 & 455 & n.o. & 420 & 280 & 140 \\
\hline
\end{tabular}

Table 1. Selected measurements of Silutitan sinensis gen. et sp. nov. (in $\mathrm{mm}$ ). “ ” indicates approximate measurements. n.o., not observable.

postzygodiapophyseal laminae (PODL) and posterior centrodiapophyseal laminae (PCDL). The cervical ribs, in turn, are present (although not complete) in all elements, except in the 12th.

The inclination of the postzygapophyses of the preserved cervical vertebrae shows some differences, with the last preserved element being more ventrolaterally directed, as observed in the posterior cervical vertebrae of other sauropods (e.g. ${ }^{78}$ ). The articulation surfaces of the postzygapophyses can only be observed in the last preserved cervical element, where they are flattened. The postzygapophyses have a stout centrodiapophyseal lamina (CPOL) as in Euhelopus and Yongjinglong ${ }^{4}$. The postzygodiapophyseal lamina (PODL) is elongated and thick, being proportionally more elongated in the new taxon compared to Erketu, Euhelopus and Qiaowanlong. Silutitan differs from Erketu and Qiaowanlong by showing a ventrolaterally bifurcated PODL, a feature previously discussed by Moore et al. ${ }^{47}$ in Euhelopus, Klamelisaurus and several "core Mamenchisaurus-like taxa". However, in Euhelopus and Klamelisaurus the ventrolaterally bifurcated PODL is observed solely on the posterior-most cervical vertebrae, while in Silutitan this feature is observed in the 9th, 10th, 12th, 14th and 15th element (Fig. 3), being less developed in the anterior-most cervical vertebrae. This persistence of the ventrally bifid PODL along most of the cervical vertebrae of Silutitan is considered an autapomorphy since, to our knowledge, this feature is not observed in any other taxa.

Silutitan also presents a variation of the development of the ventrally bifid PODL along the cervical vertebrae sequence. On the anterior-most vertebrae preserved, the bifurcation of this lamina is restricted more anteriorly and positioned almost exclusively ventrally; but on the posterior-most cervical, the bifurcation extends in length and becomes more ventrolaterally than the other cervical vertebrae. We regard the development of the ventrolaterally bifurcated PODL through the cervical series unique to Silutitan.

Silutitan presents, as other sauropods, developed epipophyses on the dorsal surface of the postzygapophyses, but unlikelythe euhelopodids Euhelopus zdanskyi ${ }^{7}$, Erketu ellisoni ${ }^{28,29}$, Phuwiangosaurus $^{23}$ and Qiaowanlon ${ }^{2}$, the epipophyses of Silutitan are elongated. The neural spines are well preserved in cervical 14 and 15, showing that they are low and reduced anteroporsteriorly.

An incomplete lower jaw of a pterosaur was recovered associated with this specimen (Fig. 3F). Despite its incompleteness, this specimen shows the same anatomy of the sole pterosaur collected in this region, Hamipterus tianshanensis ${ }^{38}$, and is therefore referred to this taxon.

SOMPHOSPONDYLI Wilson \& Sereno, 1998

TITANOSAURIA Bonaparte \& Coria, 1993

Hamititan gen. nov.

ZooBank LSID: urn:lsid:zoobank.org:act:942E2753-D90A-403C-97B2-6C2EEB4B3A95

Type species. Hamititan xinjiangensis sp. nov., type by monotypy.

Etymology. "Hami" refers to Hami city where the specimen was found, "titan", from the giants of the Greek myths and commonly used to name titanosaur taxa.

Diagnosis. The same for the species.

Hamititan xinjiangensis new species.

ZooBank LSID: urn:lsid:zoobank.org:act:FC7C98B2-B846-47C7-94FA-0513E84A9FF2

Etymology. “xinjiangensis”, refers to Xinjiang, China.

Holotype. An articulated series of seven anterior to middle caudal (HM V22), including the proximal portions of three chevrons, housed at Hami Museum (Figs. 2, 4; Table 2). 


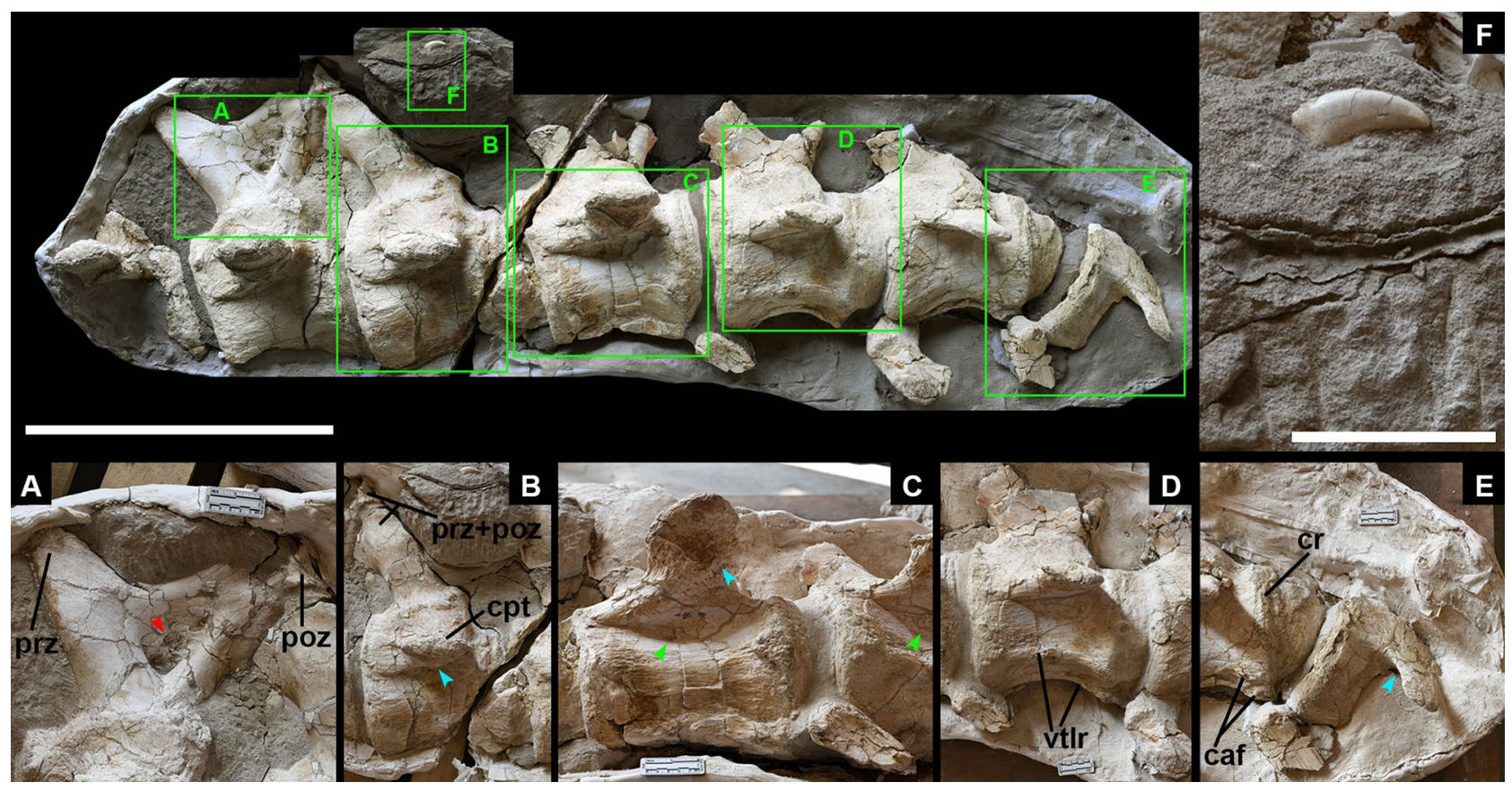

Figure 4. Hamititan xinjiangensis gen. et sp. nov., caudal sequence (HM V22) in right lateral view. Squares separated by letters indicate relevant anatomical details. (A) Neural arch of the 6th caudal showing pneumatic fossa, open inner small cavities, and the preserved prezygapophysis (prz) and postzygapophysis (poz). (B) Detail of the prezygapophyseal (prz) and postzygapophyseal (poz) articulations, and the upward oriented caudal transverse process (cpt). (C) Detailed of the caudal transverse process (cpt), with a smooth tuberosity at its ventral face (blue arrow). Green arrows show excavated lateral centra. (D) The pronounced ventrolateral ridges (vtrl) found at the anterior to middle caudal vertebrae. (E) Transverse processes abruptly changing from upward to downward on the 10th and 11th caudal vertebrae (blue arrow). The 10th caudal vertebra also shows a distinctive condylar rim (cr), and a developed chevron articulation facet (caf). (F) The theropod tooth that was found in association with this specimen. Scale bar: $50 \mathrm{~cm}$ for the whole specimen and $5 \mathrm{~cm}$ in $(\mathbf{F})$.

\begin{tabular}{|l|l|l|l|l|}
\hline & Maximum length & Maximum height & Neural arch heigth & Centrum height \\
\hline $\mathrm{Cd} 04$ & n.o. & n.o. & n.o. & $\sim 170$ \\
\hline $\mathrm{Cd} 05$ & $\sim 210$ & 380 & 190 & 190 \\
\hline $\mathrm{Cd} 06$ & 250 & 360 & 176 & $\sim 210$ \\
\hline $\mathrm{Cd} 07$ & $260^{*}$ & 330 & $\sim 140$ & $\sim 190$ \\
\hline $\mathrm{Cd} 08$ & 290 & 272 & 120 & 210 \\
\hline $\mathrm{Cd} 09$ & 320 & 263 & $\sim 90$ & 220 \\
\hline $\mathrm{Cd} 10$ & n.o. & $\sim 170$ & n.o. & 240 \\
\hline
\end{tabular}

Table 2. Selected measurements of Hamititan xinjiangensis gen. et sp. nov. (in mm). “ ” indicates approximate measurements; "^” indicates bones not fully exposed. n.o., not observable.

Locality and Horizon. Hami, Xinjiang, China; Lower Cretaceous Shengjinkou Formation (Tugulu Group).

Diagnosis. A titanosaur sauropod exhibiting the following autapomorphies: (1) tall neural arches with the neural arch higher than the height of the centrum, (2) neural arch on the anteriormost caudal sagittally expanded, (3) deep postzygapophyseal spinodiapophyseal fossa [POSDF] presenting inner open cavities on the anteriormost caudal vertebrae, (4) transverse processes on most anterior caudal vertebrae directed upwards, (5) abruptly change of orientation of the transverse processes from upward (see 3 ) to downwards. The new species is further characterized by the following combination of characters: prezygapophyses on the caudal vertebrae projecting mainly anterodorsally; and short transverse processes compressed anteroposteriorly and directed laterally.

Description and comparisons of Hamititan. Based on more complete titanosaur caudal sequences (e.g., Baurutitan $^{61}$ ), the seven caudal vertebrae of HM V22 are interpreted as being the fourth to the tenth and are here referred as such (Fig. 4). The body length of this sauropod is estimated as $17 \mathrm{~m}$ long by comparison with the length of the caudal of Rapetosaurus and Opisthocoelicaudia ${ }^{25,73}$. 
The caudal vertebrae are strongly procoelous, differing from Huanghetitan liujiaxiaensis, "Huanghetitan" ruyangensis, Baotianmansaurus, Dongyangosaurus, Gobititan, Ruyangosaurus, where they in general are amphiplatyan ${ }^{1,5,12,13,15,17,18,54}$. Huabeisaurus and Abdarainirus present opisthocoely [incipient on the former ${ }^{22,55}$ ], differing from Hamititan.

It should be noted that strongly procoelous caudal vertebrae are known for Daxiatitan ${ }^{3}$, Dongbeititan ${ }^{9}$ and Xianshanosaurus ${ }^{14}$. Hamititan shares with these taxa the lack of pleurocoels and the prezygapophyses positioned close to the proximal margin of the centrum. All four taxa also show the neural spine oriented posterodorsally. Hamititan differs from Daxiatitan ${ }^{3}$ and Dongbeititan ${ }^{9}$ by showing well-marked ventrolateral ridges. Although such ridges are also recorded in Xianshanosaurus ${ }^{54}$, the latter differs from Hamititan by having longer transverse processes that are also more horizontal ${ }^{14}$. Lastly, Hamititan differs from these three taxa by having stouter prezygapophyses ${ }^{3,9,14}$. Furthermore, Hamititan shows an abrupt change of the orientantion of the transverse processes throughout the caudal series.

The new taxon lacks internal spongy bony tissue as many titanosaurs ${ }^{84}$. The procoelous caudal vertebrae is not exclusively present in titanosaurs and has been recorded in several eusauropods such as Mamenchisaurus and Wamweracaudia keranjei ${ }^{53}$, the turiasaurian Moabosaurus utahensis ${ }^{81}$. However, in lithostrotian titanosaurs the centra presents at the condylar convex a distinct rim, which separates the condyle from the lateral surface of the main body of the centrum ${ }^{82}$. This feature is also observed in the anterior caudal and middle vertebrae of some derived titanosaurs, such as Trigonosaurus and Baurutitan and the unnamed titanosaur NHMUK R5333 $3^{82}$. The new Chinese species has the ventral surface of the centrum slightly concave anteroposteriorly (Fig. 4), as in many lithostrotians, such as Arrudatitan ${ }^{58,59}$, Baurutitan $^{62}$, Daxiatitan ${ }^{3}$, Dreadnoughtus ${ }^{63}$, Dongbeititan ${ }^{9}$ Gond- $^{-}$ wanatitan $^{66}$, Rinconsaurus ${ }^{74}$ NHMUK R5333 ${ }^{82}$, and Xianshanosaurus ${ }^{14}$.

Hamititan also presents the ventrolateral ridge as in the somphospondylans Abdarainurus ${ }^{55}$ Huabeisaurus $^{22}$ and Phuwiangosaurus ${ }^{23}$, as well as in the titanosaurs Andesaurus ${ }^{57}$, Arrudatitan $^{58}$, Malawisaurus ${ }^{70}$, Opisthocoelicaudia $^{25}$, Rapetosaurus ${ }^{73}$; Rinconsaurus ${ }^{74}$; Saltasaurus ${ }^{75}$ and Xianshanosaurus (based on the scorings of ${ }^{54}$ ). The 4th, 5th and 6th elements have a smooth excavation on the lateral surface of the centrum that does not form a pneumatopore. The chevron facets are poorly developed, being better developed on 8th and 9th vertebrae.

The neural arches are remarkably high when compared with the total height of the vertebrae (at least on 5th and 6th caudal vertebrae). The neural arches are located on the half of the centrum length on more anterior caudal vertebrae but become closer to the anterior half along the caudal series (Table 2), as in Abdarainurus ${ }^{47}$. In the most anterior caudal vertebrae, the neural arch is anteroposteriorly short at its base but broader dorsally at its end, showing a sagittal expanded neural spine, similar to Lirainosaurus ${ }^{68,69}$ and Tengrinsaurus ${ }^{76,77}$. However, Hamititan differs from this Spanish titanosaur as the neural arch that does not reach the anterior border of the centrum as in the former (Fig. 4). In lateral view, the neural arch of the caudal vertebra 5th shows a deep postzygapophyseal spinodiapophyseal fossa [POSDF] delimited by equally thick posterior spinodiapophyseal lamina (SPDL), and the postzygodiapophyseal lamina (PODL), which delimit the are much more robust than the normally presented in other sauropods-a feature so far only observed in Hamititan xinjiangensis (Fig. 4).

The prezygapophyses and the postzygapophyses are not preserved except for the 5 th and 6 th. In lateral view, the zygapophyseal pedicels on the 7th, 8th and 9th are strongly curved and directed upwards (Fig. 4), like the anterior to middle caudal vertebrae of Opisthocoelicaudia (plate 4, Fig. $1 \mathrm{~b}^{25}$ ). In caudal elements 5 and 6, the prezygapophyses are relatively long and project mainly anterodorsally. In the new species, it is more vertically oriented similar to Phuwiangosaurus ${ }^{23}$. The postzygapophysis on caudal vertebra 5 projects posterodorsally, almost reaching the posterior margin of the vertebral centrum, such as in Neuquensaurus ${ }^{71}$ and the Russian lithostrotian Tengrisaurus starkovi [ZIN PH 7/13 and ZIN PH 14/13 ${ }^{76,77}$ ]. The two centroprezygapophyseal lamina (CPRL) and the centropostzygapophyseal lamina (CPOL) are extremely robust and bounds the neural channel. There is no evidence of diapophyseal laminae on the available caudal elements of Hamititan xinjiangensis.

The neural spine is partially preserved only on the 5 th, where it is strongly directed posterodorsally as in Bonatitan [MACN-PV RN 821 ${ }^{53}$ ], Tengrisaurus starkovi [ZIN PH 7/13 ${ }^{76,77}$ ], Abdarainurus barsboldi $i^{55}$, as well as in the saltasaurines such as Neuquensaurus (e.g. ${ }^{71}$ ).

The transverse processes are placed ventral to the neural arch-centrum contact and have a triangular base, presenting a ridge-like rugosity on the ventral surface. In the 4th element they are short and become longer in the subsequent caudal vertebrae. From caudal vertebra 4th to the 9th, the transverse processes are laterally and with slight upward deflection abruptly changing to a downward deflection on the 10th and 11th. To our knowledge, such an odd and abrupt change of the deflection of transverse processes is reported for the first time in sauropods Three proximal ends of chevrons are preserved and found articulated with the 8th, 9th and 10th anterior caudal vertebrae. The proximal process is laterally compressed and curves gently backwards. Since there is no taphonomic evidence of any deformation, we regard the changes of orientation of the transverse process as an anatomical feature characteristic of this species. It should be noted that the morphology of the laminae and the transverse processes are consistent throughout the caudal series, corroborating with our interpretation.

A small theropod tooth was found associated with this caudal sequence (Fig. 4). It is very curved and has no root. The crown is strongly compressed. The subquadrangular denticles are only preserved on the middle of the distal carina.

\section{SOMPHOSPONDYLI Wilson \& Sereno, 1998}

Specimen. One incomplete sacrum (IVPP V27875) consisting of 4 fragmentary elements with co-ossified centra and some sacral ribs (Figs. 2, 5).

Locality and Horizon. Hami, Xinjiang, China; Lower Cretaceous Shengjinkou Formation (Tugulu Group). 


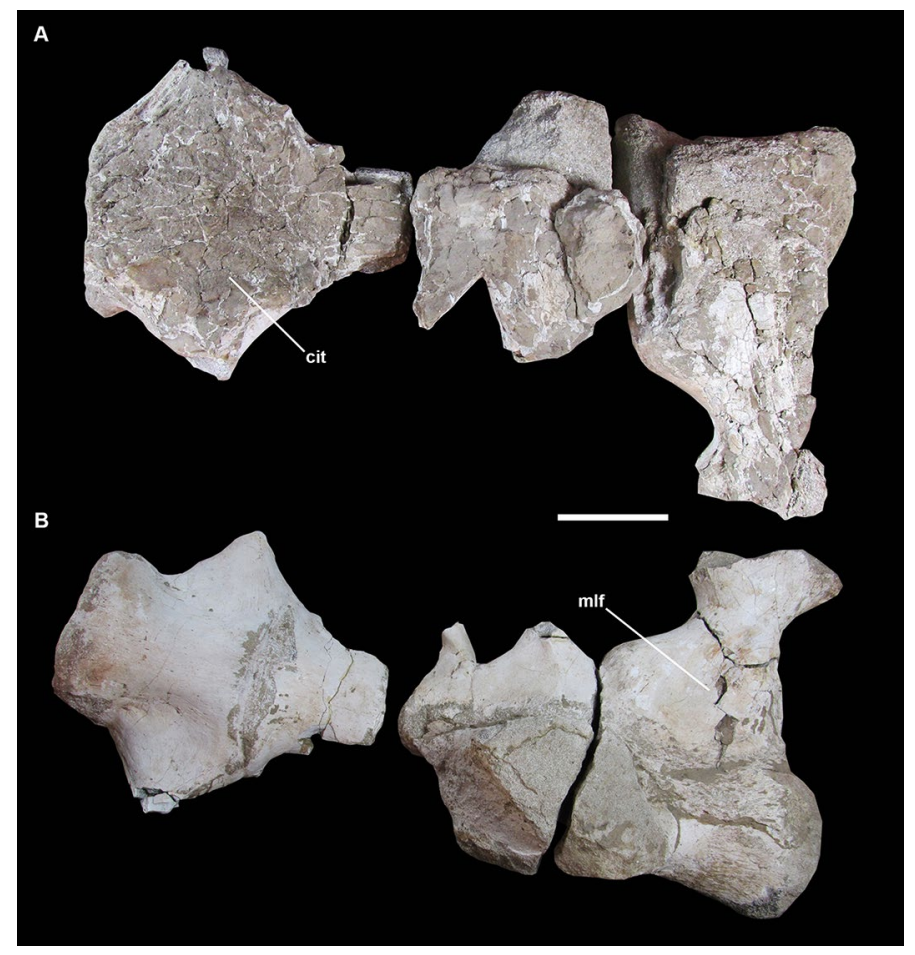

Figure 5. Sacral vertebrae (IVPP V27875), in (A) dorsal view, showing the camellate internal tissue (cit) and, (B) in ventral view, showing the mediolaterally deep fossa (mlf) on the ventral surface. Scale bar: $10 \mathrm{~cm}$.

\begin{tabular}{|c|c|c|c|c|}
\hline & Maximum length & Maximum height & Neural arch heigth & Centrum height \\
\hline Cs 02 & $\sim 280$ & n.o. & n.o. & n.o. \\
\hline Cs $04 / 05$ & 200 & n.o. & n.o. & n.o. \\
\hline
\end{tabular}

Table 3. Selected measurements of sacral vertebrae (IVPP V27875) (in mm). n.o., not observable.

Description of IVPP V27875 and comparisons. The specimen (IVPP V27875) consists of the remains of at least four incompletes sacral centra with incomplete sacral ribs. They are not completely fused, with clearly marked sutures between sacral 4 and 5 . Compared with complete somphospondylan sacra (e.g. ${ }^{22,64,72,75,78-80}$ ), we regard them tentatively to represent the sacral 2 to 5 . The most complete centra are of the sacral 2 and 5 , which are short and opisthocoelic (Table 3). In ventral view, the centra are transversely convex (Fig. 5), such as in Diamantinasaurus $^{64}$. The dorsal surface is completely eroded with the camellate internal bone exposed. On ventral view, neither centra possess external pneumatic fossae, despite the evidence of closed foramina in sacral 4 and 5 (Fig. 5). The absence of pneumatic fossa distinguishes IVPP V27875 from some somphospondylan like Phuwiangosaurus ${ }^{23}$, MLP 46-VIII-21-2 $2^{80}$, the more derivate titanosaurs Saltasaurus ${ }^{75}$ and Neuquensaurus ${ }^{72}$. This specimen also differs from Rapetosaurus ${ }^{60}$ that shows deep lateral pneumatic foramina.

The ventral surface of the centra is concave differing from MLP 46-VIII-21-2 ${ }^{80}$ and Diamantinasaurus ${ }^{64}$. The sacral ribs are robust, especially in the second sacral vertebra). The best-preserved rib is long, directed laterally and has an extensive and mediolaterally deep fossa on the ventral face (Fig. 5) that is reported for the first time in somphospondylan sauropods. Three well-developed pneumatic foramina are observed on the anteromedial surface of this rib.

Phylogenetic analysis. The phylogenetic relationships of the somphospondylans Silutitan sinensis, Hamititan xinjiangensis and IVPP V27875 (Figs. 6, 7, 8) were evaluated using the data matrices focused on Titanosauriformes published by Filippi et al. ${ }^{67}$ and Mannion et al. ${ }^{53,54}$, since those datasets are focused on somphospondylans. While the study of Filippi et al.$^{67}$, focuses on titanosaur interrelationships, Mannion et al. ${ }^{53,54}$ is more concerned with the interrelationships of somphospondylans, especially the basal ones. The data matrix was edited with Mesquite version $3.6^{85}$ and cladistic analyses were conducted using the software T.N.T. $1.5^{86}$. Unstable taxa were detected a priori, using the 'iterpcr' method in $\mathrm{TNT}^{87}$.

Since the materials studied here do not show overlapping elements, we performed three different combinations for each dataset in order to better understand the phylogenetical positioning of each specimen. First, we coded all three specimens as a single taxon. Secondly, we combined Silutitan and Hamititan as one taxon and 

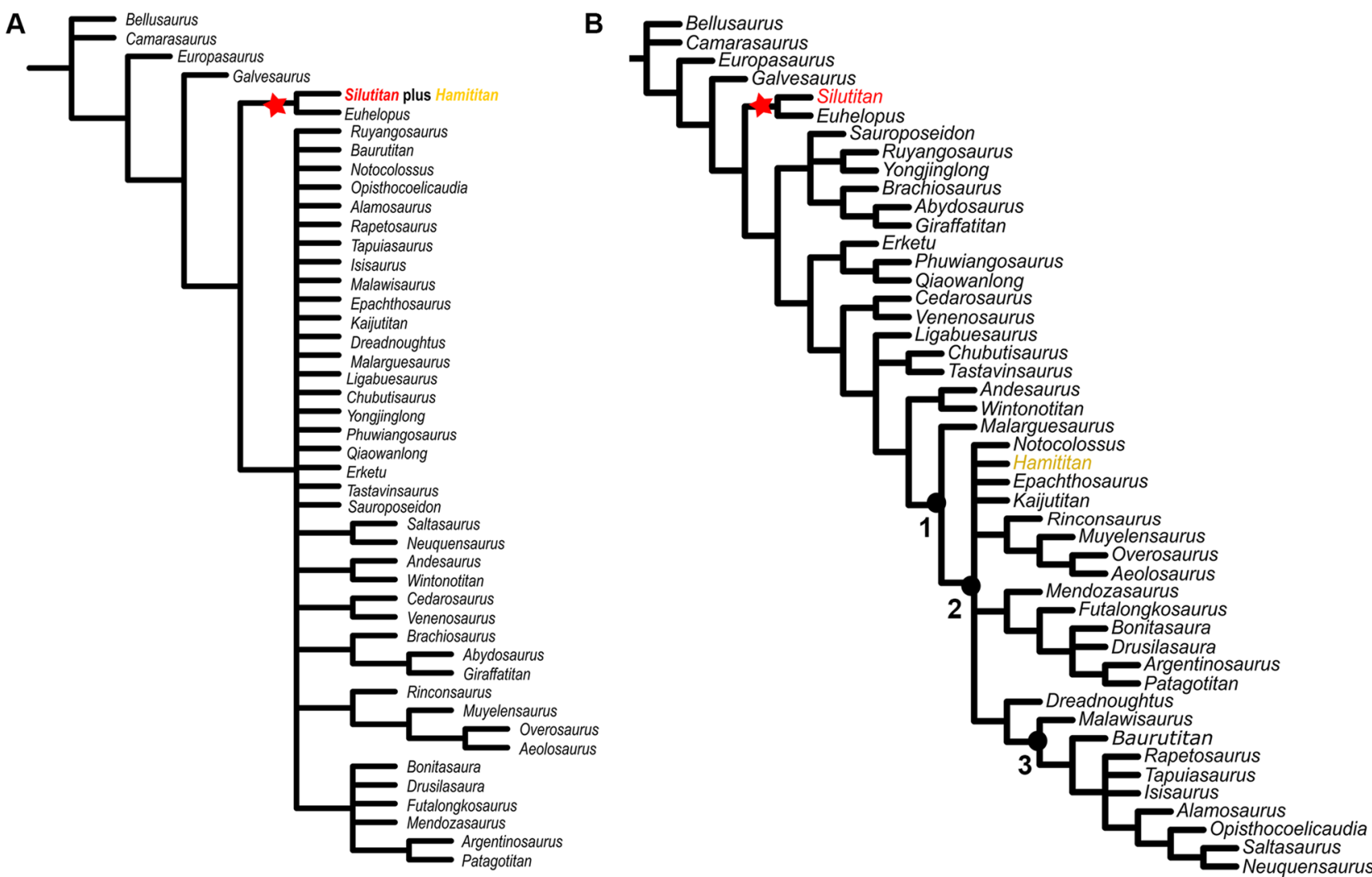

Figure 6. Strict consensus cladogram based on Filippi et al. dataset ${ }^{67}$ : (A) Silutitan sinensis and Hamititan xinjiangensis scored as a single taxon; and (B) Silutitan sinensis and Hamititan xinjiangensis scored as two separated taxa. Nodes numbers indicate the clades retrieved: 1. Titanosauria, 2. Colossosauria, and 3. Lithostrotia. Silutitan sinensis is highlighted in red and Hamititan xinjiangensis, in yellow.

excluded the sacral elements. Lastly, we coded Silutitan and Hamititan as separate taxa and excluded the sacral vertebrae (IVPP V27875) from the analyses.

Results on Filippi et al. dataset. Considering the matrix of Filippi et al. ${ }^{67}$, we could not include the sacral elements (IVPP V27875) due to lack of scorable characters in this dataset (Supplementary Information). When IVPP V27874 (Silutitan) and HM V22 (Hamititan) are regarded as representing the same taxon, 29,312 most parsimonious trees (MPTs) with 1359 steps were recovered. The strict consensus tree is much less resolved as in the original study and most of the clades are collapsed. The combined specimens (IVPP V27874 and HM V22) were found as the sister-taxon of Euhelopus, sustained only by cervical characters (Fig. 6A).

Scoring Silutitan (IVPP V27874) and Hamititan (HM V22) as separate taxa resulted in 128 MPTs of 1331 steps. The strict consensus tree is less resolved than the one of the original study. Silutitan had no effect on the topology and is recovered as the sister-taxon of Euhelopus. This relationship is supported by four characters: the shape and orientation of the parapophysis along the cervical series $(122: 0>2)$; the parapophysis shape on middle and posterior cervical vertebrae (147: $0>1)$; the epipophyses shape $(129: 0>1)$ and the lateral profile of the neural spine of the posterior cervical vertebrae $(149: 0>0)$.

Regarding Hamititan xinjiangensis (HM V22), this taxon collapses several clades at the Colossosauria node ${ }^{52}$, generating a polytomy formed by Kaijutitan, Epachthosaurus, Hamititan, and Notocolossus (Fig. 6B). If pruning method is applied, one of the pruned taxa is Hamititan.

Hamititan is nested in Colossosauria supported by the following character states: presence of pneumatized neural arch on anterior caudal vertebrae (221:1) and anterior caudal vertebrae procoelous (230:1).

Results on Mannion et al. dataset. As in the dataset before, when all three specimens were considered as the same taxon, a large polytomy for Titanosauriformes is recovered (Supplementary Information).

Mannion et al. ${ }^{54}$ used two procedures running their dataset. First, the used equal weighting and after they applied extended implied weighting with different value of $\mathrm{k}$ (see ${ }^{53,54}$ for details). Scoring IVPP V27874 (Silutitan), HM V22 (Hamititan) and IVPP V27875 as a single taxon with equal weighting resulted in 54,450 MPTs with 2672 steps. In this analysis, the composite taxon is also recovered a sister-taxon of Euhelopus but retrieved in a large polytomy with other somphospondylans. The inclusion of the two news specimens as a single taxon resulted in a much less resolved consensus tree than the one recovered in the original study ${ }^{54}$. The same results were achieved when eliminating the sacral elements (IVPP V27875) and scoring IVPP V27874 (Silutitan), HM V22 (Hamititan) as representing the same taxon (Fig. 7A). Running the dataset with the extended implied 
A

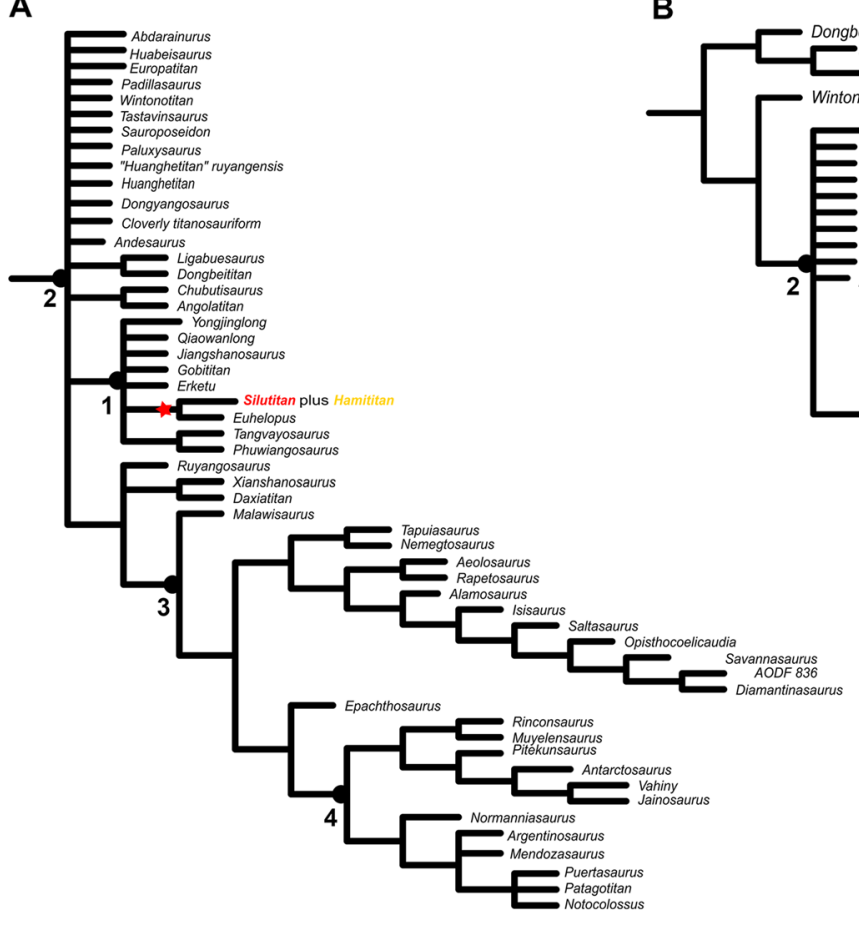

B
Figure 7. Strict consensus cladogram based on Mannion et al. dataset ${ }^{54}$, with Silutitan sinensis and Hamititan xinjiangensis scored as a single taxon: (A) applying equal weighting; and (B) applying extended implied weighting, with $\mathrm{k}$-value 9. Nodes numbers indicate the clades retrieved: 1. Euhelopodidae, 2. Titanosauria, 3. Lithostrotia, and 4. Colossosauria. Silutitan sinensis is highlighted in red and Hamititan xinjiangensis, in yellow.
B

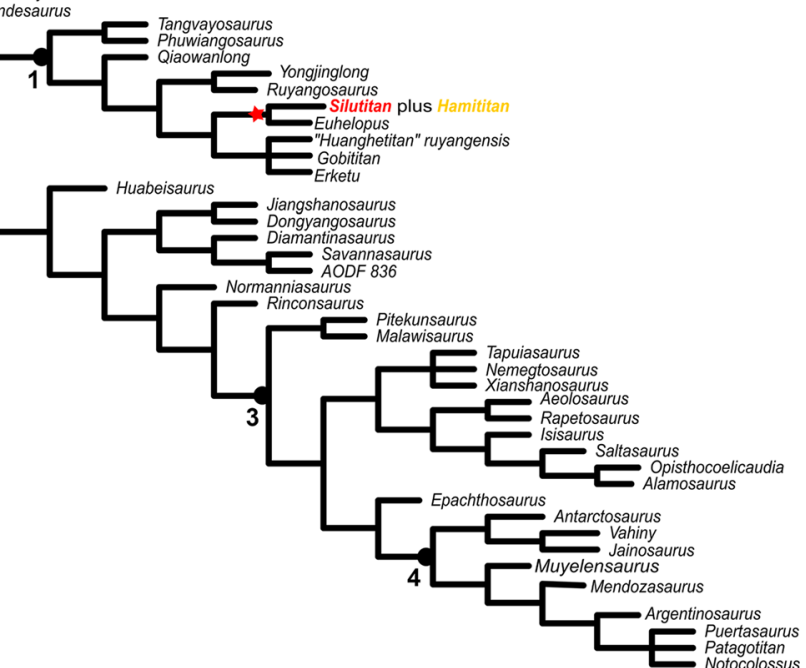

A

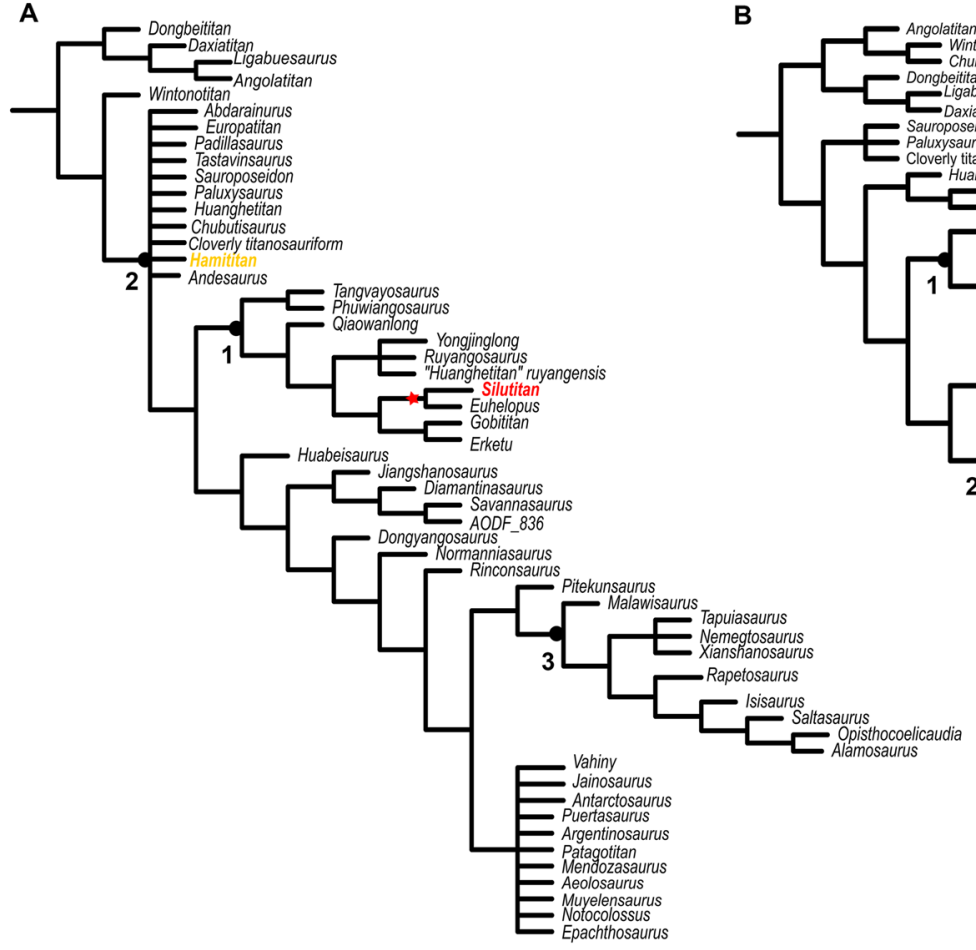

Figure 8. Strict consensus cladogram based on Mannion et al. dataset ${ }^{54}$ with Silutitan sinensis and Hamititan xinjiangensis scored as two separated taxa: (A) applying equal weighting and (B) applying extended implied weighting, with $\mathrm{k}$-value 9. Nodes numbers indicate the clades retrieved: 1. Euhelopodidae, 2. Titanosauria, 3. Lithostrotia, and 4. Colossosauria. Silutitan sinensis is highlighted in red and Hamititan xinjiangensis, in yellow. 
weighting $(\mathrm{k}=9$, Fig. 7B), has not changed the relation of Silutitan + Euhelopus but brought a better resolution within Euhelopodidae, being similar to the topology of the original study by Mannion et al. ${ }^{53,54}$.

Scoring Silutitan (IVPP V27874) and Hamititan (HM V22) as separate taxa without extended implied weighting resulted in 4148 MPTs with 2616 steps. The strict consensus is less resolved than the one published by Mannion et al. ${ }^{54}$ with only a few clades in Somphospondyli recovered. After pruning the unstable taxa, we find 2615 MPTs and most of the topology of the original study recovered (Fig. 8A). Silutitan falls as sister-taxon of Euhelopus in the Euhelopodidae, with the remaining taxa of this clade collapsed. Hamititan was recovered in a small polytomy with basal titanosaurians, outside Colossosauria (Fig. 8A). The clade formed by Silutitan + Euhelopus is supported by three characters (Char. 118: $0 \rightarrow 1$; Char. 121: $1 \rightarrow 0$, and Char. 128: $0 \rightarrow 1$ ). Hamititan is nestedad as a basal titanosaurian, what is supported by two synapomorphies (Char. 182: $0 \rightarrow 1$ and Char. 489: $1 \rightarrow 0$ ).

Running the matrix using extended implied weighting with $\mathrm{k}=9$ (Fig. 8B) recovered Hamititan as a derived titanosaur, as the sister-taxon of (Aeolosaurus + Rapetosaurus). Comparing the topologies of the consensus trees using both matrices showed the same results regarding Silutitan sinensis, always recovered as the sister-taxon of Euhelopus, suggesting that they form a separate clade within Euhelopodidae (Fig. 8B).

The position of Hamititan xinjiangensis, however, is more instable. Regarding the dataset of Filippi et al. ${ }^{67}$, this taxon is recovered as a Colossossauria, whose position regarding Rincosauria, Lithostrotia and Lognkosauria cannot be established at the time being.

Regarding the dataset of Mannion et al. ${ }^{54}$, Hamititan xinjiangensis is recovered in rather extreme positions. When equal weighting is applied, Hamititan xinjiangensis is found on the base of Titanosauria while if implied weighing is applied $(\mathrm{k}=9)$, this taxon moves to the top, as the sister-taxon of (Aeolosaurus + Rapetosaurus). Nonetheless, both datasets, shows that Hamititan xinjiangensis is well nested within Titanosauria, distant from Silutitan sinensis, corroborating that both represent quite distinct taxa.

\section{Discussion}

Comments about other East Asian sauropods. The diversity of somphospondylan sauropod genera from the Cretaceous of East Asia increased vastly in the last decades ${ }^{47,52-54}$. Several taxa, however, a lack comparable elements with Silutitan and Hamititan: Zhuchengtitan is represented by a single humerus ${ }^{19}$, Liubangosaurus consists of a set of dorsal vertebrae ${ }^{10}$, Borealosaurus known by two distal caudals, a humerus and one tooth ${ }^{16}$, and Gannansaurus erected based on one middle caudal and one posterior dorsal vertebra ${ }^{20}$.

Regarding other somphospondylans, several East Asian sauropods taxa are classified in the Euhelopodidae, whose interrelationships is still a matter of debate ${ }^{47,49-54,82}$. Qiaowanlong, Gobitian and Erketu are traditionally assigned in this group ${ }^{7,28,29,53,54,82}$ and recent phylogenetic studies have included other taxa such as Yongjinglong, Liubangosaurus, Ruyangosaurus, Huabeisaurus and "Huanghetitan" ruyangensis ${ }^{22,50,52-54}$.

Silutitan sinensis can be assigned to the Euhelopodidae based on the presence of a thick EPRL dividing the spinodiaphophyseal fossa into two subfossae, and the pendant cervical ribs. This taxon cannot be compared with the euhelopodids Gobititan, Liubangosaurus, and "Huanghetitan" ruyangensis"1,10,15 that do not show comparable elements.

Silutitan differs from Qiaowanlong ${ }^{2}$, that shows the EPRL diagonally oriented, the neural spine bifid, and two fossae on the lateral surface of the centrum of the cervical vertebrae.

The cervical vertebrae of Yonginglong differ from Silutitan by having large pleurocoels that almost occupy the entire lateral side of the cervical vertebrae ${ }^{4}$.

Silutitan can be distinguished from Euhelopus, the first discovered euhelopodid ${ }^{6,7}$ by the absence of a median turbercle on the cervical vertebrate and by having the PODL elongated and ventrolaterally bifurcated in all preserved cervical vertebrae.

Huabeisaurus differs from Silutitan by the lack of bifurcated PRDL and vertically oriented EPRL, present in the new species.

The cervical vertebrae of Ruyangosaurus are not well preserved ${ }^{11,12}$. As far as comparisons are possible, this taxon differs from Silutitan by lacking pleurocoels in the anteriormost cervical vertebrae (but having a deep and large pleurocoel in the posteriomost cervical element) and having longer centra. The two posterior-most cervical vertebrae of Ruyangosaurus are stouter than the Silutitan and show a thick and not bifurcated posterior centrodiapophyseal lamina (PCDL).

Hamititan xinjiangensis was recovered as a member of the Titanosauria. Several Early Cretaceous Chinese sauropods had been originally classified in this clade (e.g., ${ }^{4}, 17$ ), but recent studies regarded some as representing other lineages of Titanosauriformes, such as Gannansaurus ${ }^{20}$, Borealosaurus $^{16}$, Yongjinglong ${ }^{53,54}$, Dongyangosaurus and Jiangshanosaurus ${ }^{54}$. In any case, the caudal vertebrae present in Gannansaurus ${ }^{20}$ are from the posterior region of the tail, being amphycoelous and therefore differing from Hamititan. The same difference can be observed in the anterior and posterior caudal elements of Jiangshanosaurus ${ }^{54}$. Borealosaurus also has only posterior caudals ${ }^{16}$, but opisthocoelous. Huabeisaurus shows a fairly complete tail ${ }^{22}$, with the anterior being opisthocoelic while the middle and posterior are amphycoelic.

Other titanosaurian taxa recovered from China also differ from Hamititan. The putative titanosaur Dongyangosaurus has two anterior caudal vertebrae, that shows the anterior and posterior surfaces of the two caudal centra gently concave $\mathrm{e}^{18,54}$ and proportionally shorter than the ones of Hamititan.

Daxiatitan $^{3}$, Xianshanosaurus ${ }^{14}$ and Dongbeititan ${ }^{9}$ show strongly procoelous anterior caudal elements and share with Hamititan the lateral surface of the centra lacking pleurocoels, prezygapophyses positioned beyond the proximal margin of the centrum, and the neural spine oriented posterodorsally. Hamititan presents well-marked ventrolateral ridges that are absent in Dongbeititan and Daxiatitan ${ }^{3,9}$. Xianshanosaurus further differs from Hamititan by having longer and horizontally placed transverse processes ${ }^{14}$, as well as the presence of lateral openings. 
Although our phylogenetic analyses did not recover Hamititan as an euhelopodid, we have also compared this species with members of this clade. It should be noted that most taxa referred to the Euhelopodidae lack caudal elements, including Euhelopus ${ }^{7}$. Depending on the dataset, some authors do regard Tangvayosaurus, Phuwiangosaurus, Ruyangosaurus and Gobititan, originally described as titanosaurs ${ }^{1,11,12,23}$, as euhelopodids ${ }^{53,54,82}$. They differ from Hamititan by having proportionally shorter caudal vertebrae with nearly flat articular ends, presenting an amphiplatyan condition. Gobititan shows variation in some of the posterior-most caudals ${ }^{1}$, that can be slightly procoelous, but the anterior elements, as pointed out, differ from Hamititan. Hamititan further differs from all the above-mentioned taxa by having stouter prezygapophyses, taller neural arches, and presents the unique morphology of the transverse processes that show an abrupt change from being directed upward in the anterior elements to being directed downward in the posterior ones.

Comments about Euhelopodidae. The Euhelopodidae is a rather problematic clade of sauropod dinosaurs. This name was first proposed by Romer $^{88}$ containing five genera: Mamenchisaurus, Chiayusaurus, Omeisaurus, Tienshanosaurus, and Euhelopus. The original taxa of Romer have not been recovered as a clade by most of the recent phylogenetic analysis, with Euhelopus mostly recovered as Somphospondyli (e.g. ${ }^{49-54}$ ). The first phylogenetic definition of Euhelopodidae was formulated by $\mathrm{D}^{\prime} \mathrm{Emic}^{89}$ as the clade containing "neosauropods more closely related to Euhelopus zdanskyi than to Neuquensaurus australis" ( ${ }^{89}:$ pg. 626). Some authors recovered Euhelopodidae as paraphyletic with Euhelopus nested far from other euhelopodids, such as Erketu and Qiaowanlong ${ }^{49,63}$. A more extreme result was obtained by Moore et al. ${ }^{47}$ that recovered Euhelopus outside of Macronaria, highlighting the necessity of reviewing this and closely related taxa. In any case, in the phylogenetic analyses presented here, we did consistently recover we recovered Silutitan sinensis consistently as the sistertaxon of Euhelopus.

Other associated taxa. Two of the new specimens described here were found associated with elements of other taxa. Close to the 10th cervical vertebrae of Silutitan sinensis (IVPP V27874), an incomplete lower jaw attributed to the pterosaur Hamipterus tianshanensis is preserved. The association of pterosaur with sauropods have not commonly been reported in the literature $\left(\right.$ e.g. $\left.{ }^{90}\right)$. It is not clear, however, if there were any more specific palaeoecological interactions between these taxa and this association is likely due to taphonomy.

Regarding Hamititan xinjiangensis, a small theropod tooth was observed above the neural arch of the 6th caudal vertebrae. It is the first report of theropod dinosaur discovered in this area. Theropod teeth are commonly found associated with the sauropod remains, generally suggesting that theropods could have fed on their carcasses (e.g. ${ }^{91,92}$ ). Although this might also have been possible here, no evidence of tooth marks has been observed in this specimen, or on the other sauropod material described here.

\section{Conclusions}

The discovery of Silutitan sinensis and Hamititan xinjiangensis increased the sauropod diversity of Asia, particularly from an area where these vertebrates are not common. Silutitan sinensis is closely related to Euhelopus. The existence of a more inclusive clade of similar sauropods (Euhelopodidae) is still a matter of debate and pends on more detailed description of some putative euhelopodid.

Hamititan xinjiangensis is one of the few titanosaurian sauropod recovered from Asia, which shows an unusual combination of sauropod features. The presence of two somphospondylan species in the Tugulu Group novel information on somphospondylan evolution and provides further support for a widespread diversification of these sauropods during the Early Cretaceous of Asia.

\section{Materials and methods}

Anatomical terminology. We used the traditional "Romerian" terminology as proposed by Wilson ${ }^{93,94}$, using for example "anterior" rather than "cranial", as directional terms. For the identification and designation of vertebral laminae and fossae for Sauropoda we follow the landmark-based scheme proposed by Wilson ${ }^{93,94}$ and Wilson et al. ${ }^{95}$ respectively.

Heuristic tree search. The datasets of Filippi et al. ${ }^{67}$ and Mannion et al. ${ }^{53,54}$ were analyzed using the "New Technology Search". The algorithms ("Sectorial Search", "Ratchet”, "Drift” and "Tree Fusing”) are applied together with the traditional search procedures, such as Wagner Trees, Tree Branch Reconnection (TBR) and SubtreePruning-Regrafting (SPR) algorithms, to find the Minimum Length Trees (MLTs). A final round of TBR branch swapping was applied to the best trees obtained at the end of the replicates to find all of the Most Parsimonious Trees (MPTs).

Filippi et al. 2019. The matrix consists of 405 characters and 83 taxa, including Silutitan and Hamititan. The sacral vertebrae (IVPP V27875) were not included since it cannot be scored in this dataset. Characters (14, 61, $100,102,109,115,127,135,136,168,181,197,258,261,278,279,280,281,301,305,348,354$ and 356) were ordered, as in the original analysis, and using equal weighting of characters.

Mannion et al. 2019. The matrix consists of 548 characters and 120 taxa, including the new taxa described here and plus adding the scorings of Abdarainurus disponibles in ${ }^{55}$. The characters $(11,14,15,27,40,51,104,122$, $147,148,195,205,259,297,426,435,472$ and 510) were ordered, as in the original analysis and first we use equal weighting of characters. Six unstable taxa were removed after the method of ${ }^{87}$ are IVPP V27875, Katepensaurus, Abydosaurus, Losillasaurus, Futalognkosaurus and Baotianmansaurus. As in Mannion et al. ${ }^{53,54}$ additional analy- 
ses were performed, using the same pruned matrix and protocol, but applying extended implied weighting in TNT with concavity $(\mathrm{k})$ value of 9 .

Received: 23 April 2021; Accepted: 8 July 2021

Published online: 12 August 2021

\section{References}

1. You, H. L., Tang, F. \& Luo, Z. X. A new basal titanosaur (Dinosauria: Sauropoda) from the Early Cretaceous of China. Acta Geol. $\operatorname{Sin} 77,424-429$ (2003).

2. You, H. L., Li, D. Q., Zhou, L. Q. \& Ji, Q. Huanghetitan liujiaxiaensis, a new sauropod dinosaur from the Lower Cretaceous Hekou Group of Lanzhou Basin, Gansu Province, China. Geol. Rev. 52, 668-674 (2006).

3. You, H. L., Li, D. Q., Zhou, L. Q. \& Ji, Q. Daxiatitan binglingi, a giant sauropod dinosaur from the Early Cretaceous of China. Gansu Geol. 17, 1-10 (2008).

4. You, H. L. \& Li, D. Q. The first well-preserved Early Cretaceous brachiosauid dinosaur in Asia. Proc. R. Soc. Lond. Biol. 276, 4077-4082 (2009).

5. Li, L. G., Li, D. Q., You, H. L. \& Dodson, P. A new Titanosaurian Sauropod from the Hekou Group (Lower Cretaceous) of the Lanzhou-Minhe Basin, Gansu Province, China. PLoS ONE 9(1), e85979. https://doi.org/10.1371/journal.pone.0085979 (2014).

6. Wiman, C. Die Kreide-Dinosaurier aus Shantung. Palaeontologia Sinica (series C) 6, 1-67 (1929).

7. Wilson, J. A. \& Upchurch, P. Redescription and reassessment of the phylogenetic affinities of Euhelopus zdanskyi (Dinosauria: Sauropoda) from the Early Cretaceous of China. J. Syst. Palaeontol 7(2), 199-239 (2009).

8. Barrett, P. M. \& Wang, X. L. Basal titanosauriform (Dinosauria, Sauropoda) teeth from the Lower Cretaceous Yixian Formation of Liaoning Province, China. Palaeoworld 16(4), 265-271 (2007).

9. Wang, X. et al. Dongbeititan dongi, the first Sauropod Dinosaur from the Lower Cretaceous Jehol Group of Western Liaoning Province, China. Acta Geol. Sin. 81(6), 911-916 (2007).

10. Mo, J. Y., Xu, X. \& Buffetauta, E. New Eusauropod Dinosaur from the Lower Cretaceous of Guangxi Province, Southern China. Acta Geol. Sin. 84, 1328-1335 (2010).

11. Lü, J. C. et al. A new gigantic sauropod dinosaur from the Cretaceous of Ruyang, Henan, China. Geol. Bull. China 28(1), 1-10 (2009).

12. Lü, J. C. et al. Osteology of the Giant Sauropod Dinosaur Ruyangosaurus giganteus Lü et al., 2009 (Geological Publishing House, 2014).

13. Zhang, X. L. et al. A New Sauropod Dinosaur from the Late Cretaceous Gaogou Formation of Nanyang, Henan Province. Acta Geol. Sin. 83, 212-221 (2009).

14. Lü, J. C. et al. A preliminary report on the new dinosaurian fauna from the Cretaceous of the Ruyang Basin, Henan Province of central China. J. Geol. Soc. Korea 25, 43-56 (2009).

15. Lü, J. C. et al. A New Gigantic Sauropod dinosaur with the deepest known body cavity from the Cretaceous of Asia. Acta Geol. Sin. 81, 167-176 (2007).

16. You, H. L., Ji, Q., Lamanna, M. C. \& Li, Y. A titanosaurian sauropod dinosaur with opisthocoelous caudal vertebrae from the early Late Cretaceous of Liaoning Province, China. Acta Geol. Sin. 78, 907-911 (2004).

17. Tang, F., Kang, X. M., Jin, X. S., Wei, F. \& Wu, W. T. A new Sauropod dinosaur of Cretaceous from Jiangshan, Zhejiang Province. Vertebrata Palasiatica 29(4), 272-281 (2001).

18. Lü, J. C., Azuma, Y., Chen, R., Zheng, W. \& Jin, X. A New Titanosauriform Sauropod from the Early Late Cretaceous of Dongyang, Zhejiang Province. Acta Geol. Sin. 82(2), 225-235 (2008).

19. Mo, J. Y., Wang, K. B., Chen, S. Q., Wang, P. Y. \& Xu, X. A new titanosaurian sauropod from the Late Cretaceous strata of Shandong Province. Geol. Bull. China 36(9), 1501-1505 (2017).

20. Lü, J. C., Yi, L. P., Zhong, H. \& Wei, X. F. A new somphospondylan Sauropod (Dinosauria, Titanosauriformes) from the Late Cretaceous of Ganzhou, Jiangxi province of southern China. Acta Geol. Sin. 87(3), 678-685 (2013).

21. Pang, Q. \& Chang, Z. W. A new family of sauropod dinosaur from the Upper Cretaceous of Tianzhen, Shanxi Province, China. Acta Geol. Sin. 74, 1-9 (2000).

22. D’Emic, M. D. et al. Osteology of Huabeisaurus allocotus (Sauropoda: Titanosauriformes) from the Upper Cretaceous of China. PLOS ONE 8(8), e69375 (2013).

23. Suteethorn, S. et al. A new skeleton of Phuwiangosaurus sirindhornae (Dinosauria, Sauropoda) from NE Thailand. Geol. Soc. Spec. Publ. 315, 189-215 (2009).

24. Nowinski, A. Nemegtosaurus mongoliensis n. gen., n. sp., (Sauropoda) from the uppermost Cretaceous of Mongolia. Acta Palaeontol. Pol. 25, 57-81 (1971).

25. Borsuk-Bialynicka, M. A new camarasaurid sauropod Opisthocoelicaudia skarzynskii gen. n., sp. n. from the Upper Cretaceous of Mongolia. Acta Palaeontol. Pol. 37, 6-63 (1977).

26. Currie, P. J., Wilson, J. A., Fanti, F., Mainbayar, B. \& Tsogtbaatar, K. Rediscovery of the type localities of the Late Cretaceous Mongolian sauropods Nemegtosaurus mongoliensis and Opisthocoelicaudia skarzynskii: Stratigraphic and taxonomic implications. Palaeogeogr. Palaeoclimatol. Palaeoecol. 494, 5-13 (2018).

27. Averianov, A. O. \& Lopatin, A. V. Sauropod diversity in the Upper Cretaceous Nemegt Formation of Mongolia-A possible new specimen of Nemegtosaurus. Acta Palaeontol. Pol. 64(2), 313-321 (2019).

28. Ksepka, D. T. \& Norell, M. A. Erketu ellisoni, a long-necked sauropod from Bor Guvé (Dornogov Aimag, Mongolia). Am. Mus. Novit 3508, 1-16 (2006).

29. Ksepka, D. T. \& Norell, M. A. The Illusory Evidence for Asian Brachiosauridae: New Material of Erketu ellisoni and a Phylogenetic Reappraisal of Basal Titanosauriformes. Am. Mus. Novit 3700, 1-27 (2010).

30. Young, C. C. Reports of Paleontological Expedition to Sinkiang (II). Pterosaurian Fauna from Wuerho. Sinkiang. Acad. Sin. Mem. Inst. Vertebr. Palaeontol. Paleoanthropol. 11, 18-35 (1973).

31. Dong, Z. M. Dinosaurs from Wuerho. Mem. Inst. Vertebr. Paleontol. Paleoanthropol. 11, 45-52 (1973) (in Chinese).

32. Rauhut, O. W. M. \& Xu, X. The small theropod dinosaurs Tugulusaurus and Phaedrolosaurus from the Early Cretaceous of Xinjiang, China. J. Vertebr. Paleontol. 25(1), 107-118 (2005).

33. Sereno, P. C. \& Chao, S. Psittacosaurus xinjiangensis (Ornithischia: Ceratopsia), a new psittacosaur from the Lower Cretaceous of northwestern China. J. Vertebr. Paleontol. 8(4), 353-365 (1988).

34. Brinkman, D. B., Eberth, D. A., Ryan, M. J. \& Chen, P.-J. The occurrence of Psittacosaurus xinjiangensis Sereno and Chow, 1988 in the Urho area, Junggar Basin, Xinjiang, People’s Republic of China. Can. J. Earth Sci. 38, 1781-1786 (2001).

35. Xu, X. et al. Two Early Cretaceous fossils document transitional stages in alvarezsaurian dinosaur evolution. Curr. Biol. 28, 2853-2860 (2018). 
36. Brusatte, S. L., Benson, R. B. J. \& Xu, X. A reassessment of Kelmayisaurus petrolicus, a large theropod dinosaur from the Early Cretaceous of China. Acta Palaeontol. Pol. 57(1), 65-72 (2012).

37. Upchurch, P., Barrett, P. M. \& Dodson, P. Sauropoda. In The Dinosauria 2nd edn (eds Weishampel, D. B. et al.) 259-322 (University of California Press, 2004).

38. Wang, X. L. et al. Sexually dimorphic tridimensionally preserved pterosaurs and their eggs from China. Curr. Biol. 24, 1323-1330 (2014).

39. Wang, X. L. et al. Comparison of biodiversity of the Early Cretaceous pterosaur faunas in China. Earth Sci. Front. 27(06), 347-364 (2020).

40. Wang, X. L. et al. Egg accumulation with 3D embryos provides insight into the life history of a pterosaur. Science 358, 1197-1201 (2017).

41. Wang, X. L., Jiang, S. X. \& Cheng, X. Study on Hamipterus and their 3D embryos. Sci. Technol. Rev. 36(23), 11-19 (2018).

42. Kellner, A. W. A., Weinschütz, L. C., Holgado, B., Bantim, R. A. M. \& Sayão, J. M. A new toothless pterosaur (Pterodactyloidea) from Southern Brazil with insights into the paleoecology of a Cretaceous desert. An. Acad. Bras. Ciênc. 91(Suppl. 2), e2019076801-32 (2019).

43. Martill, D. M. Palaeontology: Which came first, the pterosaur or the egg?. Curr. Biol. 24, R615-R617 (2014).

44. Deeming, D. C. How pterosaurs bred. Science 358(6367), 1124-1125 (2017)

45. Zhao, X. J. Mesozoic vertebrate-bearing beds and stratigraphy of northern Xinjiang. In Reports of Paleontological Expedition to Sinkiang (IV) 63-77 (Science Press, 1980).

46. You, H. L., Morschhauser, E. M., Li, D. Q. \& Dodson, P. Introducing the Mazongshan Dinosaur Fauna. J. Vertebr. Paleontol. 38, $1-11(2018)$.

47. Moore, A. J., Upchurch, P., Barrett, P. M., Clark, J. \& Xu, X. Osteology of Klamelisaurus gobiensis (Dinosauria, Eusauropoda) and the evolutionary history of Middle-Late Jurassic Chinese sauropods. J. Syst. Palaeontol. 18, 1299-1393 (2020).

48. Wang, X. R. et al. A new titanosauriform dinosaur (Dinosauria: Sauropoda) from Late Jurassic of Junggar Basin, Xinjiang. Glob. Geol. 38(3), 581-588 (2019).

49. Carballido, J. L. et al. A new giant titanosaur sheds light on body mass evolution among sauropod dinosaurs. Proc. R. Soc. Lond. Biol. 284(1860), 20171219 (2017).

50. González-Riga, B. J., Mannion, P. D., Poropat, S. F., Ortiz-David, L. \& Coria, J. P. Osteology of the Late Cretaceous Argentinean sauropod dinosaur Mendozasaurus neguyelap: Implications for basal titanosaur relationships. Zool. J. Linn. Soc. 184(1), 136-181 (2018).

51. Wilson, J. A. Sauropod dinosaur phylogeny: Critique and cladistic analysis. Zool. J. Linn. Soc. 136, 217-276 (2002).

52. González-Riga, B. J. et al. An overview of the appendicular skeletal anatomy of South American titanosaurian sauropods, with definition of a newly recognized clade. An. Acad. Bras. Ciênc 91(2), e20180374 (2019).

53. Mannion, P. D., Upchurch, P., Schwarz, D. \& Wings, O. Taxonomic affinities of the putative titanosaurs from the Late Jurassic Tendaguru Formation of Tanzania: Phylogenetic and biogeographic implications for eusauropod dinosaur evolution. Zool. J. Linn. Soc. 185, 784-909 (2019).

54. Mannion, P. D., Upchurch, P., Jin, X. S. \& Zheng, W. J. New information on the Cretaceous sauropod dinosaurs of Zhejiang Province, China: Impact on Laurasian titanosauriform phylogeny and biogeography. R. Soc. Open Sci. 6(8), 191057 (2019).

55. Averianov, A. \& Lopatin, A. An unusual new sauropod dinosaur from the Late Cretaceous of Mongolia. J. Syst. Palaeontol. https:// doi.org/10.1080/14772019.2020.1716402 (2020).

56. Calvo, J. O. \& Bonaparte, J. F. Andesaurus delgadoi gen. et sp. nov. (Saurischia- Sauropoda), dinosaurio Titanosauridae de la Formación Río Limay (Albiano- Cenomaniano), Neuquén, Argentina. Ameghiniana 28, 303-310 (1991).

57. Mannion, P. D. \& Calvo, J. O. Anatomy of the basal titanosaur (Dinosauria, Sauropoda) Andesaurus delgadoi from the mid-Cretaceous (Albian-early Cenomanian) Río Limay Formation, Neuquén Province, Argentina: Implications for titanosaur systematics. Zool. J. Linn. Soc. 153, 1-27 (2011).

58. Santucci, R. M. \& Arruda-Campos, A. C. A new sauropod (Macronaria, Titanosauria) from the Adamantina Formation, Bauru Group, Upper Cretaceous of Brazil and the phylogenetic relationships of Aeolosaurini. Zootaxa 3085, 1-33 (2011).

59. Silva, J.C. Jr. et al. Reassessment of Aeolosaurus maximus, a titanosaur dinosaur from the Late Cretaceous of Southeastern Brazil. Hist. Biol. (2021) (in Press).

60. Bandeira, K. L. N. et al. A New Giant Titanosauria (Dinosauria: Sauropoda) from the Late Cretaceous Bauru Group. Brazil. PLoS ONE 11(10), e0163373 (2016).

61. Salgado, L., Gallina, P. A. \& Paulina-Carabajal, A. Redescription of Bonatitan reigi (Sauropoda: Titanosauria), from the CampanianMaastrichtian of the Río Negro Province (Argentina). Hist. Biol. 27(5), 525-548 (2014).

62. Kellner, A. W. A., Campos, D. A. \& Trotta, M. N. F. Description of a titanosaurid caudal series from the Bauru Group, Late Cretaceous of Brazil. Arq. do Mus. Nac 63, 529-564 (2005).

63. Lacovara, K. J. et al. A gigantic, exceptionally complete Titanosaurian Sauropod dinosaur from southern Patagonia, Argentina. Sci. Rep 4, 6196 (2014).

64. Poropat, S. F. et al. Revision of the sauropod dinosaur Diamantinasaurus matildae Hocknull et al. 2009 from the middle Cretaceous of Australia: Implications for Gondwanan titanosauriform dispersal. Gondwana Res. 27, 995-1033 (2015).

65. Martínez, R. D., Giménez, O., Rodríguez, J., Luna, M. \& Lamanna, M. C. An articulated specimen of the basal titanosaurian (Dinosauria: Sauropoda) Epachthosaurus sciuttoi from the early Late Cretaceous Bajo Barreal Formation of Chubut province, Argentina. J. Vertebr. Paleontol. 24, 107-120 (2004).

66. Kellner, A. W. A. \& Azevedo, S. A new sauropod dinosaur (Titanosauria) from the Late Cretaceous of Brazil. Nat. Scien. Mus. Monogr. 15, 111-142 (1999).

67. Filippi, L. S., Salgado, L. \& Garrido, A. C. A new giant basal titanosaur sauropod in the Upper Cretaceous (Coniacian) of the Neuquén Basin, Argentina. Cretac. Res. 100, 61-81 (2019).

68. Sanz, J. L., Powell, J. E., Martinez, R. \& J.L.L., \& Pereda-Suberbiola, X. ,. Sauropod remains from the Upper Cretaceous of Laño (north central Spain). Titanosaur phylogenetic relationships. Estudios del Museo de Ciencias Naturales de Alava 14(1), 235-255 (1999).

69. Díez Díaz, V., Pereda Suberbiola, X. \& Sanz, J. L. The axial skeleton of the titanosaur Lirainosaurus astibiae (Dinosauria: Sauropoda) from the latest Cretaceous of Spain. Cretac. Res. 43, 145-160 (2013).

70. Gomani, E. M. Sauropod dinosaurs from the Early Cretaceous of Malawi. Palaeontol. Electron. 8, 1-37 (2005).

71. Salgado, L., Apesteguía, S. \& Heredia, S. E. A new specimen of Neuquensaurus australis, a Late Cretaceous Saltasaurinae titanosaur from North Patagonia. J. Vertebr. Paleontol. 25, 623-634 (2005).

72. D'Emic, M. D. \& Wilson, J. A. New remains attributable to the holotype of the sauropod dinosaur Neuquensaurus australis, with implications for saltasaurine systematics. Acta Palaeontol. Pol. 56, 61-73 (2011).

73. Curry, R. K. The postcranial osteology of Rapetosaurus krausei (Sauropoda: Titanosauria) from the Late Cretaceous of Madagascar. J. Verteb. Paleontol. 29, 1046-1086 (2009).

74. Calvo, J. O. \& Riga, B. J. G. Rinconsaurus caudamirus gen. et sp. Nov., a new titanosaurid (Dinosauria, Sauropoda) from the Late Cretaceous of Patagonia, Argentina. Rev Geol Chile 30(2), 333-353 (2003).

75. Powell, J.E. Osteología de Saltasaurus loricatus (Sauropoda-Titanosauridae) del Cretácico Superior del noroeste Argentino. In Los dinosaurios y su entorno biotico: Actas del Segundo Curso de Paleontología em Cuenca (eds Sanz, J. et al.) 165-230 (1992). 
76. Averianov, A. \& Skutschas, P. A new lithostrotian titanosaur (Dinosauria, Sauropoda) from the Early Cretaceous of Transbaikalia, Russia. Commun. Biol. 62(1), 6-18 (2017).

77. Averianov, A. O., Sizov, A. V. \& Skutschas, P. P. Gondwanan affinities of Tengrisaurus, Early Cretaceous titanosaur from Transbaikalia, Russia (Dinosauria, Sauropoda). Cretac. Res 122, 104731 (2021).

78. Campos, D. A., Kellner, A. W. A., Bertini, R. J. \& Santucci, R. M. On a titanosaurid (Dinosauria, Sauropoda) vertebral column from the Bauru Group, Late Cretaceous of Brazil. Arq. do Mus. Nac. 63(3), 565-593 (2005).

79. Campos, A. D., \& Kellner, A. W. A. On some Titanosauridae pelves from the continental cretaceous of Brazil. In Proceedings, Vol. 15 (eds Tomida, Y. et al.) 143-166 (1999).

80. Filippini, F. A., Otero, A. \& Gasparini, Z. The phylogenetic relevance of the sacrum among macronarian sauropods: Insights from a pelvis from the Upper Cretaceous of Patagonia, Argentina. Alcheringa 41, 69-78 (2016).

81. Britt, B. B., Scheetz, R. D., Whiting, M. F. \& Wilhite, D. R. Moabosaurus utahensis, n. gen., n. sp., a new sauropod from the Early Cretaceous (Aptian) of North America. Contrib. Museum Paleontol. Univ. Mich. 32, 189-243 (2017).

82. Mannion, P. D., Upchurch, P., Barnes, R. N. \& Mateus, O. Osteology of the Late Jurassic Portuguese sauropod dinosaur Lusotitan atalaiensis (Macronaria) and the evolutionary history of basal titanosauriforms. Zool. J. Linn. Soc. 168, $98-206$ (2013).

83. Mocho, P., Royo-Torres, R., Malafaia, E., Escaso, F. \& Ortega, F. First occurrences of non-neosauropod eusauropod procoelous caudal vertebrae in the Portuguese Upper Jurassic record. Geobios 50, 23-36 (2017).

84. Poropat, S. F. et al. Osteology of the wide-hipped Titanosaurian Sauropod Dinosaur Savannasaurus elliottorum from the Upper Cretaceous Winton formation of Queensland, Australia. J. Vertebr. Paleontol 40(3), e1786836 (2020).

85. Maddison, W. P.\& Maddison, D. R. Mesquite: a modular system for evolutionary analysis. Version $3.61 \mathrm{http}: / / \mathrm{www} . \mathrm{mesquitepr}$ oject.org (2019).

86. Goloboff, P. A. \& Catalano, S. A. TNT version 1.5, including a full implementation of phylogenetic morphometrics. Cladistics 32(3), 221-238 (2016).

87. Pol, D. \& Escapa, I. H. Unstable taxa in cladistic analysis: Identification and the assessment of relevant charaters. Cladistics $\mathbf{2 5}$, 515-527 (2009).

88. Romer, A. S. Osteology of the Reptiles 772 (University of Chicago Press, 1956).

89. D'Emic, M. D. The early evolution of titanosauriform sauropod dinosaurs. Zool. J. Linn. Soc. 166, 624-671 (2012).

90. Calvo, J. O., Porfiri, J. D., González-Riga, B. J. \& Kellner, A. W. A. Anatomy of Futalognkosaurus dukei Calvo, Porfiri, González Riga \& Kellner, 2007 (Dinosauria, Titanosauridae) from the Neuquén Group (Late Cretaceous), Patagonia, Argentina. Arq. Mus. Nac. Rio Jan. 65, 511-526 (2007).

91. Buffetaut, E. \& Suteethorn, V. A sauropod skeleton associated with theropod teeth in the Upper Jurassic of Thailand: Remarks on the taphonomic and paleoecological significance of such associations. Palaeo3 73, 77-83 (1989).

92. Kellner, A. W. A. et al. On a new titanosaur sauropod from the Bauru Group, Late Cretaceous of Brazil. Bol. Mus. Nac. 74, 1-31 (2006).

93. Wilson, J. A. A nomenclature for vertebral laminae in sauropods and other saurischian dinosaurs. J. Vertebr. Paleontol. 19, 639-653 (1999).

94. Wilson, J. A. New vertebral laminae and patterns of serial variation in vertebral laminae of sauropod dinosaurs. Contrib. Mus. Paleontol. Univ. Mich. 32, 91-110 (2012).

95. Wilson, J. A., D’Emic, M. D., Ikejiri, T., Moacdieh, E. M. \& Whitlock, J. A. A nomenclature for vertebral fossae in sauropods and other saurischian dinosaurs. PLoS ONE 6, e17114 (2011).

\section{Acknowledgements}

We thank to Y. Li , L. Xiang, H.-J. Zhou, W. Gao, Q.-G. Liu, X. Meng, R.-J Wang, H. Wang (IVPP) and H.-P. Dai, J. Tong, R.-J. Cao (Hami) for the assistance in the field work. We also thank to L. Xiang, H.-J. Zhou, R.-J Wang and $\mathrm{H}$. Wang for the preparation of these specimens, W. Gao for photography, and Maurílio Oliveira for the sauropod sketches. We thank X.-D. Gou and Z. Feng (Yunnan University) for the help to prepare Figure 1. We thank A.S. Brum, L.G. Souza, and B. A. Navarro for providing helpful comments regarding phylogeny. We are indebted to Verónica Díez Díaz and Philip Manion for comments on earlier version of the manuscript that greatly improved this paper. We also appreciate the support from Z.-H. Zhou (IVPP) and X.-W. Zhang, Y. Paidoula, G.-L. Wu, B.-L. Guan, F. Yan, H.-Y. Chen, K. Reheman Y.-L. Tian (Hami). This study was supported by the National Natural Science Foundation of China (41688103, 41572020, 42072017), the Strategic Priority Research Program (B) of CAS (XDB18000000, XDB26000000), the Youth Innovation Promotion Association CAS (2019075), the Excavation Funding and Emphatic Deployed Project of IVPP, CAS, the Cooperation Project with Hami Government, and GASA. The Fundação de Desenvolvimento Carlos Chagas Filho de Amparo à Pesquisa do Estado do Rio de Janeiro (FAPERJ \#E-26/202.905/2018 to AWAK), the Conselho Nacional de Desenvolvimento Científico e Tecnológico (CNPq \#420687/2016-5 and \#313461/2018-0 to AWAK).

\section{Author contributions}

X.L.W., A.W.A.K. designed the research; X.L.W. and Y.X.M. organized the curation and preparation of the specimen; X.C., K.L.N.B. and S.X.J. prepared the Figures, K.L.N.B., R.Q. and X.L.W. performed the anatomical descriptive research and the phylogenetic analysis; K.L.N.B., R.Q. X.L.W. and A.W.A.K. wrote the main part of the manuscript. All authors contributed and reviewed the manuscript.

\section{Competing interests}

The authors declare no competing interests.

\section{Additional information}

Supplementary Information The online version contains supplementary material available at https://doi.org/ 10.1038/s41598-021-94273-7.

Correspondence and requests for materials should be addressed to X.W. or A.W.A.K.

Reprints and permissions information is available at www.nature.com/reprints.

Publisher's note Springer Nature remains neutral with regard to jurisdictional claims in published maps and institutional affiliations. 
(c) (i) Open Access This article is licensed under a Creative Commons Attribution 4.0 International cc) License, which permits use, sharing, adaptation, distribution and reproduction in any medium or format, as long as you give appropriate credit to the original author(s) and the source, provide a link to the Creative Commons licence, and indicate if changes were made. The images or other third party material in this article are included in the article's Creative Commons licence, unless indicated otherwise in a credit line to the material. If material is not included in the article's Creative Commons licence and your intended use is not permitted by statutory regulation or exceeds the permitted use, you will need to obtain permission directly from the copyright holder. To view a copy of this licence, visit http://creativecommons.org/licenses/by/4.0/.

(C) The Author(s) 2021 